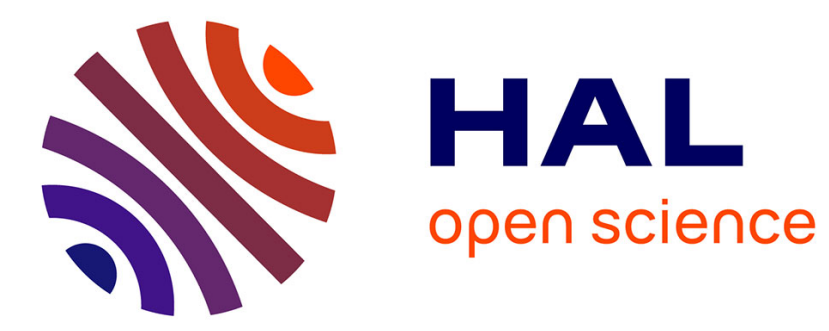

\title{
Experimental and numerical investigation of the influence of thermal boundary conditions on premixed swirling flame stabilization
}

R. Mercier, T. F. Guiberti, A. Chatelier, D. Durox, O. Gicquel, N. Darabiha, Thierry Schuller, Benoit Fiorina

\section{To cite this version:}

R. Mercier, T. F. Guiberti, A. Chatelier, D. Durox, O. Gicquel, et al.. Experimental and numerical investigation of the influence of thermal boundary conditions on premixed swirling flame stabilization. Combustion and Flame, 2016, 171, p. 42-58. 10.1016/j.combustflame.2016.05.006 . hal-01405801

\section{HAL Id: hal-01405801 \\ https://hal.science/hal-01405801}

Submitted on 30 Mar 2020

HAL is a multi-disciplinary open access archive for the deposit and dissemination of scientific research documents, whether they are published or not. The documents may come from teaching and research institutions in France or abroad, or from public or private research centers.
L'archive ouverte pluridisciplinaire HAL, est destinée au dépôt et à la diffusion de documents scientifiques de niveau recherche, publiés ou non, émanant des établissements d'enseignement et de recherche français ou étrangers, des laboratoires publics ou privés. 


\title{
Experimental and numerical investigation of the influence of thermal boundary conditions on premixed swirling flame stabilization
}

\author{
R. Mercier ${ }^{\mathrm{a}}$, T.F. Guiberti ${ }^{\mathrm{b}}$, A. Chatelier ${ }^{\mathrm{b}, \mathrm{c}}$, D. Durox ${ }^{\mathrm{b}}$, O. Gicquel $^{\mathrm{b}}$, N. Darabiha ${ }^{\mathrm{b}}$, \\ T. Schuller ${ }^{\mathrm{b}}$, B. Fiorina ${ }^{\mathrm{b}, *}$ \\ a SAFRAN Tech, Rue des Jeunes Bois, Châteaufort - CS 80112, 78772 Magny-les-Hameaux, France \\ ${ }^{\mathrm{b}}$ Laboratoire EM2C, CNRS, CentraleSupélec, Université Paris-Saclay, Grande Voie des Vignes, 92295 Châtenay-Malabry CEDEX, France \\ ' ONERA, BP72 - 29 avenue de la Division Leclerc, 92322 Châtillon CEDEX, France
}

\begin{abstract}
This paper focuses on the experimental and numerical investigation of the shape taken by confined turbulent $\mathrm{CH}_{4} / \mathrm{H}_{2}$ /air premixed flames stabilized over a bluff-body swirling injector. Two configurations, which correspond to two levels of $\mathrm{H}_{2}$ enrichment in the $\mathrm{CH}_{4} / \mathrm{H}_{2}$ fuel blend, are investigated. Experiments show that high $\mathrm{H}_{2}$ concentrations promote $\mathrm{M}$ flame shapes, whereas $\mathrm{V}$ flame shapes are observed for lower values of $\mathrm{H}_{2}$ enrichment. In both cases, non-reacting and reacting flow Large Eddy Simulation (LES) calculations were performed. Numerical results are compared with detailed velocimetry measurements under non-reacting and reacting conditions, $\mathrm{OH}$-laser induced fluorescence and $\mathrm{OH}^{*}$ chemiluminescence measurements. All temperatures of solid walls of the experimental setup including the combustor dump plane, the injector central rod tip, the combustor sidewalls and the quartz windows were also characterized. Assuming a fully adiabatic combustion chamber, LES always predicts an $\mathrm{M}$ flame shape and does not capture the $\mathrm{V}$ to $\mathrm{M}$ shape transition observed in the experiments when the hydrogen concentration in the fuel blend is increased. By accounting for non-adiabaticity using measured thermal boundary conditions, simulations predict the correct flame stabilization for both $\mathrm{V}$ and $\mathrm{M}$ flames and show a good agreement with experiments in terms of flame shape. Key features that need to be included in non-adiabatic simulations are finally stressed out.
\end{abstract}

\section{Introduction}

In many combustors operating in the lean premixed combustion regime, the flame is stabilized by a swirling flow. By promoting recirculation zones composed of burnt gases, flame stabilization is enhanced over a wide range of operating conditions [1]. The flow structure in a combustor equipped with a swirling injector is very complex [2] and either $\mathrm{M}$ or $\mathrm{V}$ flame shapes can be observed. The shape taken by the flame then affects the temperature field in the burnt gases at the outlet of the combustion chamber and pollutant emissions. Experiments and simulations indicate that the topology of swirling flames is highly sensitive to fuel composition [3-5] and heat transfer to the combustion chamber walls [6-10]. Simulations of the stabilization regimes of these flames are very challenging as numerous physical phenomena such as the combustion chemistry, flame interactions with turbulence, and heat losses have to be taken into account.

In this way, modeling efforts are continuously conducted to improve the description of detailed chemistry effects in turbulent combustion simulations [11]. In particular, Large Eddy Simulations (LES) turbulent combustion models based on tabulated chemistry have been recently improved by several groups to account for the influence of heat transfer on the flame stabilization process [12-14]. These numerical strategies have been targeted on the same Turbulent Stratified Flame (TSF) experiments conducted at the Technical University of Darmstadt (TUD) [15]. A joined comparative study between simulations and experimental data shows that while each adiabatic computations predict a flame anchored on the burner lip, all non-adiabatic simulations agree on a flame lift-off of one half pilot diameter [16]. These last results lead to a better agreement with experimental measurements of temperature and species concentrations [16]. However, being unconfined and non-swirled, the TSF configuration validates only partially the ability of a turbulent combustion model to capture flame stabilization process in a gas turbine like combustor. To achieve the validation, 
complementary experimental configurations, more representative of combustion chamber with a swirling flow are required.

Tay Wo Chong et al. [8] analyzed numerically the influence of heat losses on the shape taken by the flame in a confined swirled non-adiabatic combustor. They accounted for heat losses in Reynolds Averaged Navier-Stokes (RANS) simulations to reproduce the $\mathrm{V}$ flame shape observed through chemiluminescence imaging experiments. However, as accurate measurements of the thermal boundary conditions and flame shape were not available in this study, the comparisons between simulations and experiments remained qualitative. Proch et al. [9] modeled the effects of heat losses in a model gas turbine combustor where it was shown that non-adiabatic computations allow a better prediction of the flame shape and length in comparisons to adiabatic simulations. In this study, the wall temperatures were not measured and a fixed temperature of $T=1000 \mathrm{~K}$ was imposed for all the combustor walls. In [7], Nogenmyr et al. imposed realistic measured temperature profiles in the non-adiabatic LES of a reduced-scale confined burner. However, temperature measurements were not realized on the same burner geometry and with the same fuel as in the simulation.

The objective of the present work is first to propose a configuration which challenges the ability of turbulent combustion model to capture swirled premixed flame stabilization mechanisms in a confined geometry. The combustion chamber recently studied experimentally at the EM2C laboratory is retained for that purpose [6]. It was shown that the $\mathrm{V}$ to $\mathrm{M}$ flame shape transitions observed in this experiment are controlled by heat losses and fuel composition. As boundary conditions (inlet velocity profiles and wall temperatures) were characterized in this combustor [6], the resulting experimental database is a useful benchmark target for turbulent combustion model validation. The second objective is to test the suitability of the model F-TACLES (Filtered Tabulated Chemistry for LES) [17], recently developed to account for the impact of heat losses on detailed chemistry $[14,18]$, to capture such complex flame stabilization mechanisms.

The article is organized as follows. The experimental configuration is first presented. The diagnostics and the numerical strategies along with the investigated operated conditions are secondly described. Two configurations, which correspond to two levels of $\mathrm{H}_{2}$ enrichment in the fuel blend, are investigated. Experiments show that high $\mathrm{H}_{2}$ concentrations promote $M$ flame shapes, whereas $\mathrm{V}$ flame shapes are observed for lower values of $\mathrm{H}_{2}$ enrichment. An analysis is then carried out to examine the ability of F-TACLES to capture both $\mathrm{V}$ and $\mathrm{M}$ flame stabilization processes.

\section{Experimental setup}

\subsection{Geometry}

The experimental setup presented in Fig. 1 was used in [6] for the study of the impact of heat losses on the shape of confined swirling flames. The burner, fed by mixtures of methane $\left(\mathrm{CH}_{4}\right)$, hydrogen $\left(\mathrm{H}_{2}\right)$ and air, includes a cylindrical injection tube with a $14 \mathrm{~mm}$ exit diameter. The flow is put in rotation by a radial swirling vane located upstream of the injection tube. The radial swirler features 12 blades with an angle $\theta=35^{\circ}$ and a $4 \mathrm{~mm}$ span. The swirl number $S^{P I V}=0.33$ has been measured at the burner outlet using Particle Image Velocimetry (PIV) in longitudinal and transversal planes under non-reacting conditions. A $6 \mathrm{~mm}$ diameter central rod installed on the burner axis helps anchoring the flame at the injection unit outlet $2 \mathrm{~mm}$ above the combustor dump plane. The mixture enters the burner through a plenum and subsequently passes through a set of grid/honeycomb/grid arrangement before entering a water-cooled convergent nozzle to reach a nearly uniform top hat velocity profile at the entrance of the

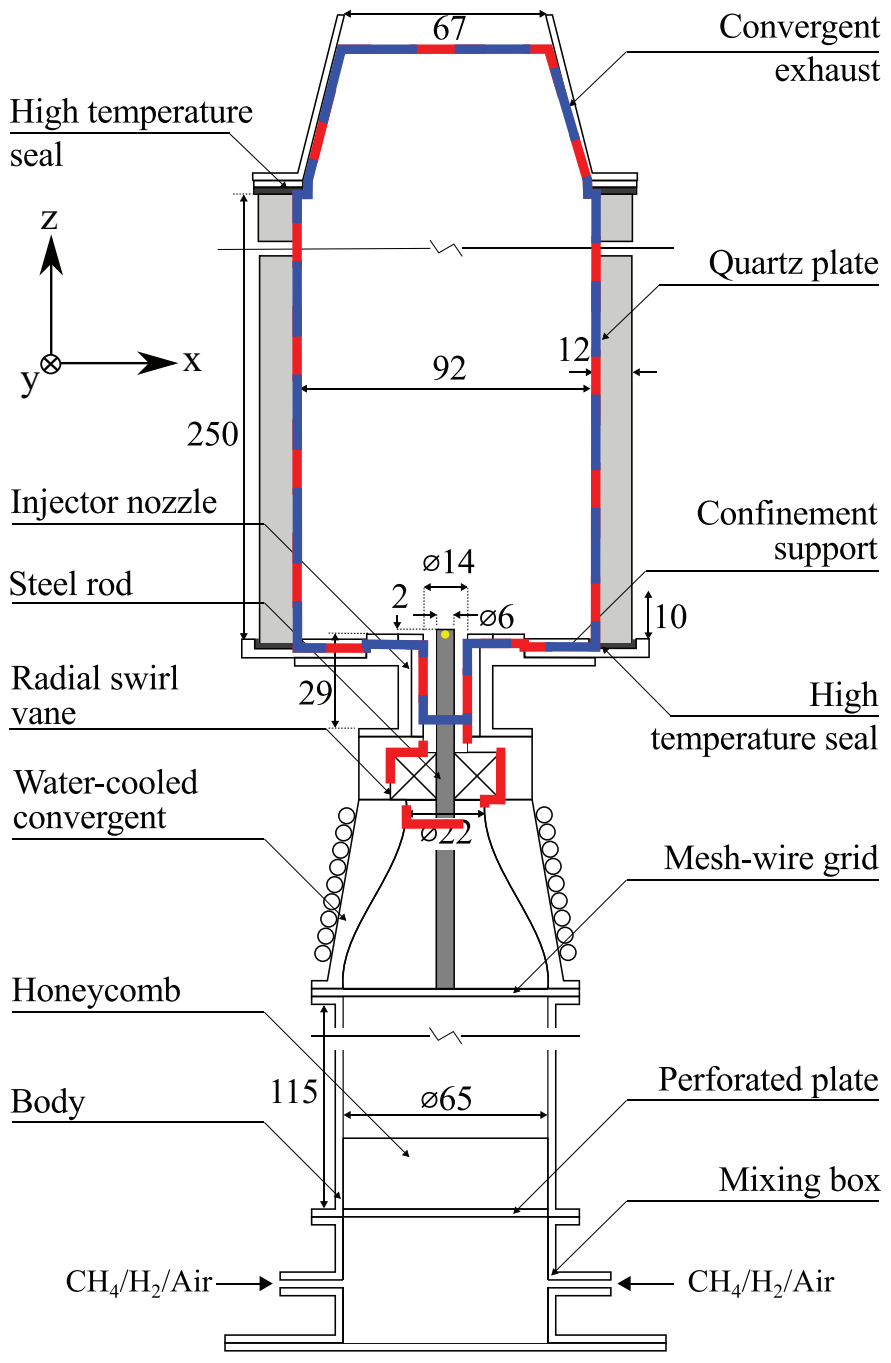

Fig. 1. Schematic of the test-rig. Dimensions are in $\mathrm{mm}$. The reference computational domain for both non-reacting and reacting cases is delimited by the blue dashed line. The red dashed line represents the preliminary computational domain used to extract the velocity boundary conditions for the reference domain. The yellow dot at the tip of the central rod indicates the origin of the numerical frames. (For interpretation of the references to color in this figure legend, the reader is referred to the web version of this article.)

swirler. The flame is stabilized in the combustion chamber featuring four $250 \mathrm{~mm}$ (height) $\times 92 \mathrm{~mm}$ (width) $\times 12 \mathrm{~mm}$ (thickness) quartz windows. The windows are maintained using four vertical steel-bars not sketched in Fig. 1. To prevent ambient air intrusion at the combustor outlet, a convergent exhaust, featuring a $53 \%$ reduction of its section, is added on the top of the chamber to accelerate the outgoing flow.

\subsection{Operating conditions}

Experiments in [6] show that flame stabilization is strongly influenced by heat losses at the combustor wall. In addition, transitions between $\mathrm{V}$ and $\mathrm{M}$ flame shapes are observed when increasing the $\mathrm{H}_{2}$ concentration in the $\mathrm{CH}_{4} / \mathrm{H}_{2}$ fuel blend. Two fuel compositions of $\left\{\mathrm{X}_{\mathrm{H}_{2}}^{\text {fuel }}=0.6 ; \mathrm{X}_{\mathrm{CH}_{4}}^{\text {fuel }}=0.4\right\}$ and $\left\{\mathrm{X}_{\mathrm{H}_{2}}^{\text {fuel }}=0.9 ; \mathrm{X}_{\mathrm{CH}_{4}}^{\text {fuel }}=0.1\right\}$ are retained for this study, where $\mathrm{X}_{\mathrm{H}_{2}}^{\text {fuel }}$ and $\mathrm{X}_{\mathrm{CH}_{4}}^{\text {fuel }}$ denote the volumetric concentration of $\mathrm{H}_{2}$ and $\mathrm{CH}_{4}$ in the fuel. For all cases, the flame power is $P=4 \mathrm{~kW}$ and the equivalence ratio is set to $\phi=0.7$. The mass flows of the different dry gases injected are regulated by thermal mass flow controllers. The mixture composition and bulk 
Table 1

Simulated cases.

\begin{tabular}{lllll}
\hline $\begin{array}{l}\text { Fuel } \\
\text { composition }\end{array}$ & $\begin{array}{l}\text { Flame } \\
\text { shape }\end{array}$ & $\begin{array}{l}\text { LES } \\
\text { assumption }\end{array}$ & $\begin{array}{l}\text { Mesh } \\
\text { (Nb. nodes) }\end{array}$ & Simu. \# \\
\hline- & - & Non-reacting & $8.6 \mathrm{M}$ & S0 \\
$\mathrm{X}_{\mathrm{H}_{2}}^{\text {fuel }}=0.6$ & $\mathrm{~V}$ & $\begin{array}{l}\text { Adiabatic } \\
\text { Non-adiabatic }\end{array}$ & $\begin{array}{l}8.6 \mathrm{M} \\
8.6 \mathrm{M}\end{array}$ & $\mathrm{S} 1$ \\
& & S2 \\
$\mathrm{X}_{\mathrm{H}_{2}}^{\text {fuel }}=0.9$ & $\mathrm{M}$ & Non-adiabatic & $67.2 \mathrm{M}$ & $\mathrm{S} 2 \mathrm{R}$ \\
\hline
\end{tabular}

flow velocity at the injection tube outlet are known with a relative accuracy better than $5 \%$. Experiments were conducted at bulk flow velocities close to $U_{\text {bulk }}=14 \mathrm{~m} \mathrm{~s}^{-1}$ at the injector outlet for gases injected at room temperature $(T=293 \mathrm{~K})$. Non-reacting experiments are also conducted by substituting the fuel by air and conserving the same bulk flow velocity. The investigated cases are listed in Table 1. Experiments show that a $\mathrm{V}$ flame shape is observed for $\mathrm{X}_{\mathrm{H}_{2}}^{\text {fuel }}=0.6$ whereas a $\mathrm{M}$ flame shape is detected for $\mathrm{X}_{\mathrm{H}_{2}}^{\text {fuel }}=0.9$.

\subsection{Velocity measurements}

Particle Imaging Velocimetry (PIV) was used to characterize the flow under reacting and non-reacting conditions. The PIV apparatus features a $2 \times 400 \mathrm{~mJ} \mathrm{Nd}$ :YAG laser doubled at $532 \mathrm{~nm}$ and operated at $10 \mathrm{~Hz}$ (Continuum, Powerlite SL3-PIV), and a $1600(\mathrm{H})$ $\times$ 1200(V)-pixels dual-shot CCD camera (Dantec Dynamics, Flow Sense). To reduce interference from the flame chemiluminescence and the ambient light, a $10 \mathrm{~nm}$ bandpass filter centered at $532 \mathrm{~nm}$ was placed in front of the camera lens. The laser sheet produced in vertical or horizontal planes has a $50 \mathrm{~mm}$ height and a relatively wide thickness of $2 \mathrm{~mm}$ to minimize out of sheet particle displacements of the swirling flow between the two laser pulses separated by a time duration $\Delta t$. The optimal duration $\Delta t$ depends on the maximum velocity that one wishes to measure and ranges from $5 \mu \mathrm{s} \leq \Delta t \leq 40 \mu \mathrm{s}$ in the experiments that were conducted. This delay is adapted to obtain a maximum particle displacement in the images comprised between 6 and 8 pixels.

The Dantec Dynamics software was used for images processing. A three passes window deformation technique comprising $128 \times 128,64 \times 64$ and finally $32 \times 32$ pixels interrogation areas with a $50 \%$ overlap is applied for correlations of the images. As an illustration, this leads to a vector spacing of $636 \mu \mathrm{m}$ in both directions for PIV experiments conducted in an axial plane with a flame, yielding 25.2 pixels per $\mathrm{mm}$.

The algorithm used accounts for the subpixel displacement of particles. The typical precision is 0.1 pixel, which corresponds to a maximum precision on velocity measurements of $0.25 \mathrm{~m} \mathrm{~s}^{-1}$. The flow is seeded with micrometric $\mathrm{ZrO}_{2}$ particles (Fisher Scientific Zirconium (IV) oxyde, Z/1850/50) for reacting experiments. The size distribution of the solid $\mathrm{ZrO}_{2}$ particles is not known with precision, but the $D_{10}$ is smaller than $5 \mu \mathrm{m}$. The Stokes number of solid particles calculated with $D_{10}=5 \mu \mathrm{m}$, a bulk flow velocity $U_{\text {bulk }}=14 \mathrm{~m} \mathrm{~s}^{-1}$, burnt gases at $1881 \mathrm{~K}$, and the injection tube diameter $D_{i}=14 \mathrm{~mm}$, is $\mathrm{Stk} \simeq 0.2$. Under non-reacting conditions, solid particles are replaced by micrometric oil droplets $\left(D_{10}=\right.$ $2.75 \mu \mathrm{m}$ and $D_{32}=4.94 \mu \mathrm{m}$ ) seeded into the flow by a nebulizer fully described in [19]. The Stokes number of these oil droplets calculated with $D_{10}=2.75 \mu \mathrm{m}$, a bulk flow velocity $U_{\text {bulk }}=14 \mathrm{~m} \mathrm{~s}^{-1}$, air at room temperature, and the injection tube diameter $D_{i}=$ $14 \mathrm{~mm}$, is Stk $\simeq 0.02$.

For the non-reacting case, the direct integration of the measured velocity profiles at the exit of the injection tube using PIV data at $z=2 \mathrm{~mm}$ gives a bulk jet velocity of $U_{\text {bulk }}^{\text {PIV }}=14.1 \mathrm{~m} \mathrm{~s}^{-1}$, corresponding to less than $1 \%$ difference with the prescribed bulk jet velocity $U_{\text {bulk }}=14 \mathrm{~m} \mathrm{~s}^{-1}$.

\subsection{Flame position measurements}

Laser Induced Fluorescence of the hydroxyl radical (OH-PLIF) measurements are carried out to delineate the location of the flame front and hot burnt gases and infer the shape taken by the flame in a vertical plane. The LIF system comprises a dye laser (Continuum, ND6000) with Rhodamine 590 dye, pumped by a Nd:YAG laser (Continuum, Precision) operated at $10 \mathrm{~Hz}$, and delivering $20 \mathrm{~mJ}$ per pulse. The laser was tuned to excite the $Q_{1}(6)$ transition of the $(1,0)$ band of the $A^{2} \Sigma-X^{2} \Pi$ system of $\mathrm{OH}$ at $282.927 \mathrm{~nm}$. Fluorescence from the $\mathrm{OH}(\mathrm{A}-\mathrm{X})(1,1)$ and $(0,0)$ bands was collected with a UV lens (UV-NIKKOR $105 \mathrm{~mm}$ ) and imaged during a 50 ns gate opening onto a $1024 \times 1024$-pixels ICCD camera (Princeton Instruments, PIMax) equipped with a $10 \mathrm{~nm}$ bandpass filter (Asahi Spectra Co., ZBPA310) centered at $310 \mathrm{~nm}$. The longitudinal laser sheets has a $50 \mathrm{~mm}$ width and a $0.5 \mathrm{~mm}$ thickness. No attempts to correct for flat-field or beam energy variations were made.

Images highlighting the mean shape taken by the flame are constructed by determining the probability of being in hot burnt gases as in [6]. We do not infer the mean $\mathrm{OH}$ molar fraction at a given location but the probability to detect $\mathrm{OH}$ i.e. burnt gases at this location. The method used for the calculation of probability for $\mathrm{OH}$ detection is now described. Instantaneous snapshots are first binarized to separate zones filled with hot burnt gases from cooler regions of the flow. Due to noise and external perturbations, regions without $\mathrm{OH}$ may feature a background signal. An intensity threshold is applied to remove these pixels. The probability of $\mathrm{OH}$ presence at each location is obtained by summing a set of $\mathrm{N} 1024$ $\times 1024$ pixels binarized OH-PLIF images and finally dividing each pixel value by the number $\mathrm{N}$ of images that were taken. The resulting image is a $1024 \times 1024$ pixels binary image where a pixel value of 1 means that the corresponding region is always filled with hot burnt gases. A value of 0 indicates a region filled with fresh reactants or cold burnt gases featuring no OH-PLIF signal. To achieve a satisfying convergence of the probabilities, the number of images $\mathrm{N}$ is always larger than 1000 in this study.

The shape taken by the flame can also be deduced from chemiluminescence measurements. The chemiluminescence of excited hydroxyl radicals $\left(\mathrm{OH}^{*}\right)$ was here imaged onto the same $1024 \times 1024$-pixels ICCD camera (Princeton Instruments, PIMax) equipped with a $10 \mathrm{~nm}$ bandpass filter (Asahi Spectra Co., ZBPA310) centered at $310 \mathrm{~nm}$. The single shot integration time was set to $200 \mu \mathrm{s}$ and 500 images were summed to obtain fully converged mean images with a total integration time of $100 \mathrm{~ms}$. Due to the important section expansion between the cylindrical injection tube and the square chamber, the flames keep their axisymmetric structure [6]. An Abel deconvolution was then applied on the mean images to infer the $\mathrm{OH}^{*}$ emission from the axial longitudinal plane. This signal is a good indicator of the heat release rate for perfectly premixed flames [20].

\subsection{Wall temperature measurements}

By altering the temperature field in the recirculating burnt gases, heat losses alter flame stabilization as shown in [6]. LES are then extremely sensitive to the prescription of thermal boundary conditions, which are here carefully measured for the two reacting configurations listed in Table 1. Figure 2 shows the position of the temperature measurement points at the different combustor wall surfaces. Under reacting conditions, all the measurements were performed after thermal steady-state was reached. A type-K thermocouple located in one of the four vertical steel bars of the 


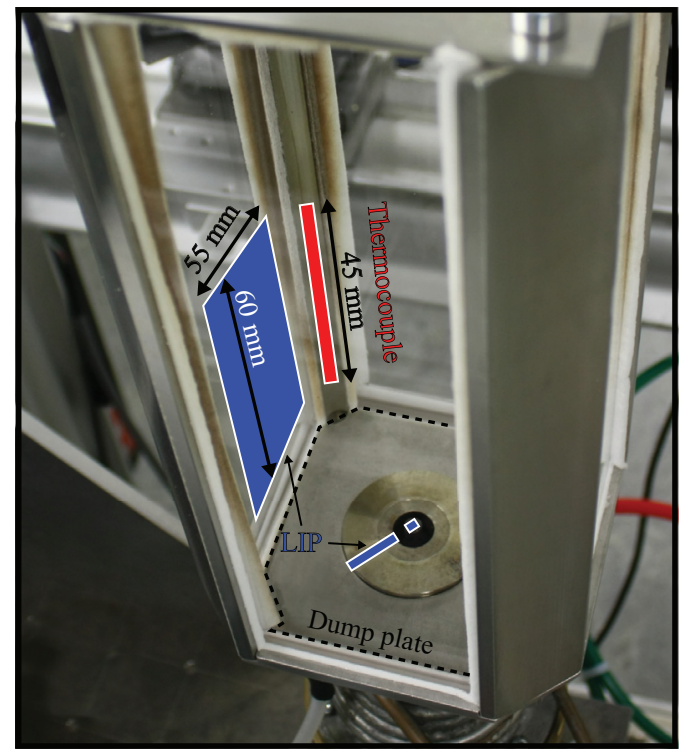

Fig. 2. Photograph of the combustion chamber showing the location of temperature measurements for the characterization of the thermal boundary conditions in the combustor.

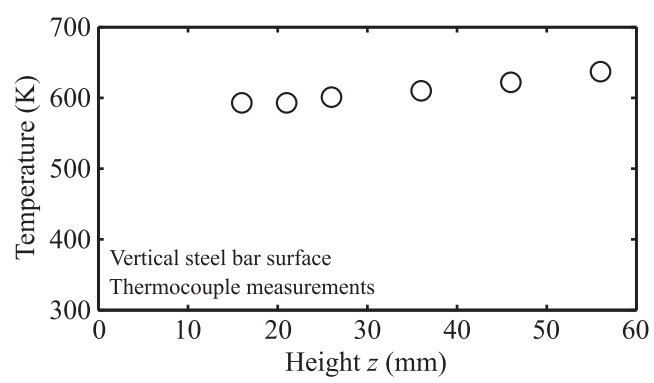

Fig. 3. Temperature profiles along the vertical steel bar as a function of the height $z$ above the rod tip. $\mathrm{CH}_{4} / \mathrm{H}_{2} /$ air flame at $P=4 \mathrm{~kW}, \mathrm{X}_{\mathrm{H}_{2}}^{\text {fuel }}=0.60$, and $\phi=0.7$.

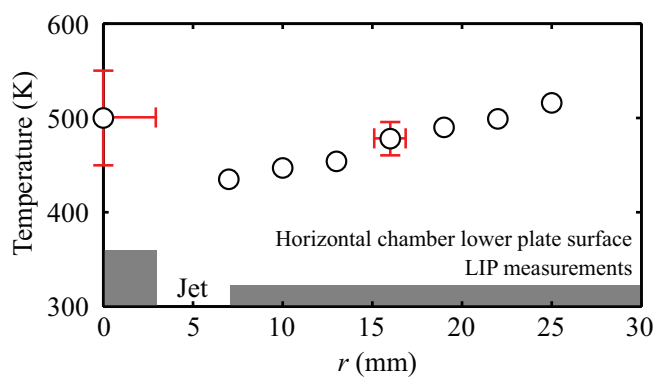

Fig. 4. Temperatures measured by LIP on the combustor dump plane as a function of the radial distance $r . \mathrm{CH}_{4} / \mathrm{H}_{2} /$ air flame at $P=4 \mathrm{~kW}, \mathrm{X}_{\mathrm{H}_{2}}^{\text {fuel }}=0.60$, and $\phi=0.7$. The grey regions indicate the location of solid surfaces. Error bars are shown in red. (For interpretation of the references to color in this figure legend, the reader is referred to the web version of this article.)

combustion chamber records the evolution of the wall temperature after ignition and measurements are realized when it reaches thermal steady-state $(\approx 45 \mathrm{~min})$.

Results are presented here for the $\mathrm{V}$ flame case (Table 1 ). The vertical temperature profile along the surface of one of the four vertical steel bars of the combustion chamber is measured using 6 type $\mathrm{K}$ thermocouples and is plotted in Fig. 3. The temperature increases slightly and almost linearly with the distance to the dump plate, from $T=593 \mathrm{~K}$ at $z=16 \mathrm{~mm}$ to $T=637 \mathrm{~K}$ at $z=56 \mathrm{~mm}$.
Figure 4 shows the measured radial profile of the temperature at the surface of the injector and along the dump plane. These data were obtained by Laser Induced Phosphorescence (LIP) measurements [21]. A phosphorescent mixture composed of $\mathrm{Mg}_{3.5} \mathrm{FGeO}_{5}$ :Mn powders (Phosphor Technology Ltd, EQD25/N-U1) and a high temperature binder (ZYP-HPC) was first deposited on the surfaces of interest i.e. one combustion chamber quartz window and on the dump plane of the combustor. We used the fourth harmonic (266 nm) of a Nd:YAG laser (Continuum, Minilite ML II) operated at $10 \mathrm{~Hz}$ to excite the phosphorescent mixture. The resulting phosphorescent signal was collected by a photomultiplier tube (Hamamatsu, R9880U-20). More details about the LIP setup are given in [6].

The temperature near the injector linearly increases with the radial distance for $r>7 \mathrm{~mm}$ and ranges from $T=435 \mathrm{~K}$ at $r=$ $7 \mathrm{~mm}$ to $T=516 \mathrm{~K}$ at $z=25 \mathrm{~mm}$. The temperature on the rod tip surface is $T=500 \pm 50 \mathrm{~K}$ and is averaged both spatially and temporally. The mean temperature indicated in Fig. 4 is the average value over more than 500 measurements realized at a repetition rate of $10 \mathrm{~Hz}$. Shot-to-shot variations of the temperature measured at the rod tip do not exceed $15 \mathrm{~K}$. The $1 \mathrm{~mm}$ diameter laser beam impacts the phosphor layer deposited on the horizontal rod tip surface with an angle of $55^{\circ}$, relative to the surface normal leading to a trace of about $1.8 \mathrm{~mm}$ diameter. This value gives an idea of the spatial resolution of the technique. Temperature gradients are large at the tip of the $6 \mathrm{~mm}$ diameter rod and the $1.8 \mathrm{~mm}$ spatial resolution is not deemed sufficient to resolve accurately the radial profile of temperature. However scanning of the LIP beam on the rod tip suggests that a single range of values $T=500 \pm 50 \mathrm{~K}$ describes well the range of temperatures reached at the rod tip. This hot temperature emphasizes the heat transfer taking place between the flame and the burnt gases filling the Internal Recirculation Zone (IRZ) and the central rod tip that is cooled by the high velocity jet of fresh gases.

LIP was also used to measure the temperature at different positions over the surface of a quartz window as shown in Fig. 2. Figure 5 shows the temperature for 30 measurement points regularly distributed over this surface. The wall temperature increases with the distance above the injector and is minimum close to the vertical steel bars featuring lower temperatures. Temperature differences along the $x$ axis can reach $\Delta T=27 \mathrm{~K}$. Temperature differences along the $z$ axis can reach $\Delta T=140 \mathrm{~K}$. This figure also shows that the quartz window temperature is not uniform along the $x$ and $z$ directions. A linear interpolation of these data shows that the temperature field is not perfectly symmetric with respect to the vertical symmetry axis of the window. This is attributed to the swirling motion of the flow. The swirling flow has an azimuthal velocity altering heat transfers to the walls. This analysis demonstrates the impact of swirl on the thermal state of the combustor walls.

The wall temperatures presented in Figs. 3-5 are lower than the adiabatic flame temperature $T_{a d}=1881 \mathrm{~K}$ for $\mathrm{X}_{\mathrm{H}_{2}}^{\text {fuel }}=0.60$, and $\phi=0.7$. This confirms that significant heat losses take place in this combustor.

Additional temperature measurements were conducted in the ORZ filled with non-adiabatic burnt gases that were presented in [6]. The mean gas temperature was measured at different locations within the ORZ by introducing type $\mathrm{K}$ thermocouples, featuring a diameter of $1.5 \mathrm{~mm}$, through one of the four vertical steel bar holding the quartz windows. Due to the relatively low temperature reached by the flow in this region $(T<1200 \mathrm{~K})$, measurement errors related to radiance at the tip of the $1.5 \mathrm{~mm}$ diameter thermocouples tip do not exceed 5\%. Consequently, temperature measurements presented in this paper were not corrected for radiance. More details about radiance correction of thermocouple measurements in hot flows can be found in [22-24]. These temperatures 


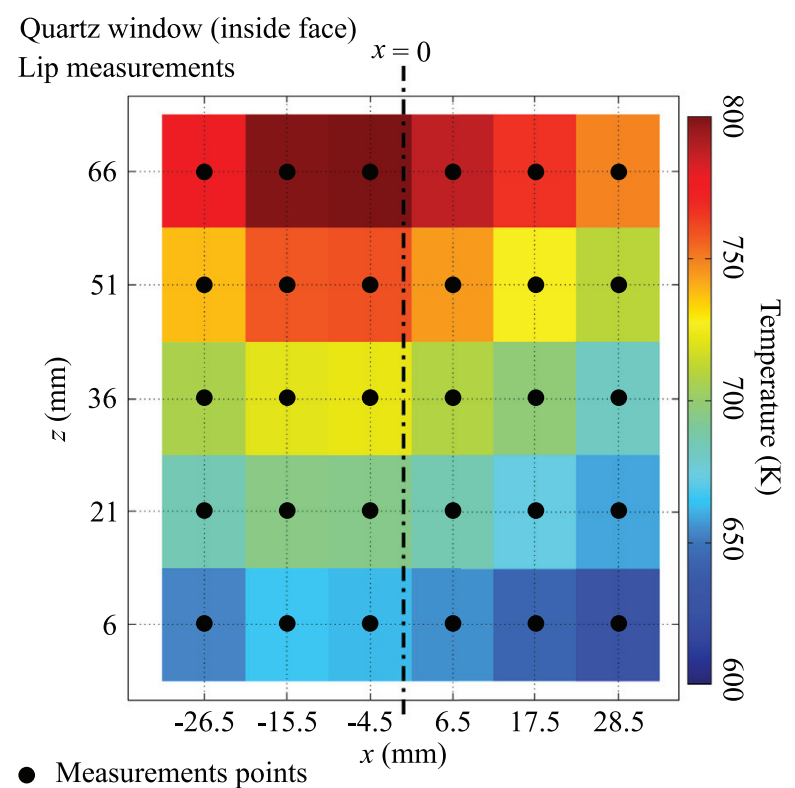

Quartz window (inside face)

Lip measurements (interpolated)

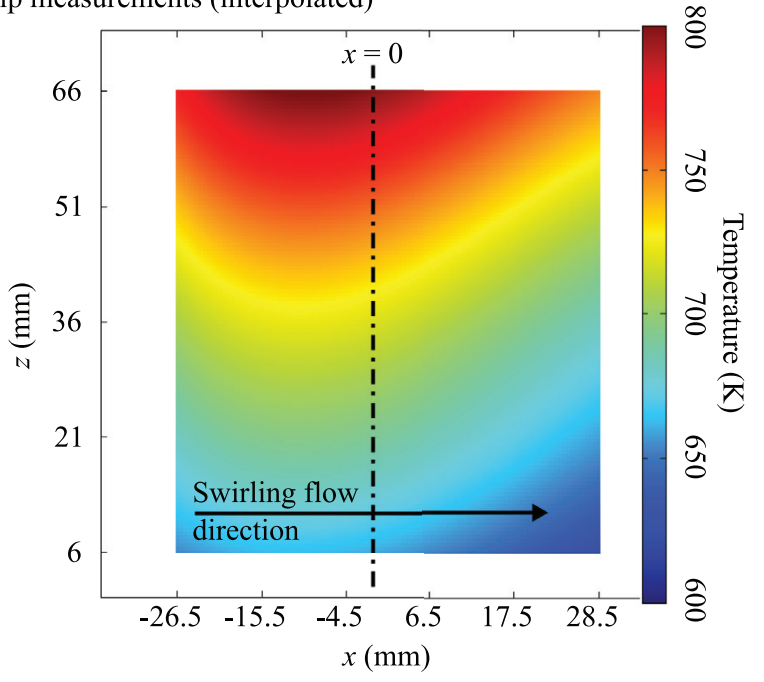

Fig. 5. Top: Temperatures, measured by LIP at the inner surface of a quartz window of the combustion chamber, of a $\mathrm{CH}_{4} / \mathrm{H}_{2} /$ air flame at $P=4 \mathrm{~kW}, \mathrm{X}_{\mathrm{H}_{2}}^{\text {fuel }}=0.60$ and $\phi=0.7$. Bottom: Linear interpolation of the data presented above. The dasheddotted lines indicate the vertical symmetry axis of the windows.

at the wall surfaces and within the flow are used to fix the thermal boundary conditions in the simulations presented below and validate the predictions.

\section{Numerical and modeling strategies}

\subsection{Turbulent combustion modeling}

Reacting numerical simulations are performed with the turbulent combustion model F-TACLES (Filtered Tabulated Chemistry for LES) based on the tabulation of filtered 1-D premixed flames [17], extended to account for heat losses in [14]. The flame front is captured by the progress variable $Y_{c}$, equal to 0 and $Y_{c}^{e q}$ in fresh and burnt gases, respectively.

The F-TACLES model consists in solving the filtered progress variable $\widetilde{Y}_{c}$ balance equation, closed under flamelet regime as follows [14]:

$$
\begin{aligned}
\frac{\partial \bar{\rho} \widetilde{Y}_{c}}{\partial t}+\nabla \cdot\left(\bar{\rho} \widetilde{\mathbf{u}} \widetilde{Y}_{c}\right)= & \nabla \cdot\left(\Xi_{\Delta} \gamma \alpha_{Y_{c}}^{a d} \rho_{0} D_{0} \nabla \widetilde{Y}_{c}\right) \\
& +\Xi_{\Delta} \gamma\left(\Omega_{Y_{c}}^{a d}+\bar{\rho} \widetilde{\dot{\omega}}_{Y_{c}}^{a d}\right)
\end{aligned}
$$

where $\rho$ and $\mathbf{u}$ are the flow density and velocity, respectively. Subscript 0 denotes reference quantities. The functions $\alpha_{Y_{c}}^{a d}, \Omega_{Y_{c}}^{a d}$ and $\widetilde{\tilde{\omega}}_{Y_{c}}^{\text {ad }}$ in Eq. (1) are designed to model the sub-grid scale (SGS) laminar contributions to molecular diffusion, convection and chemical reaction, respectively. They are tabulated by filtering 1-D adiabatic premixed flame elements computed including detailed chemistry and complex transport and stored as a function of $\widetilde{Y}_{c}$, and the filter scale $\Delta$ :

$\alpha_{Y_{c}}^{a d}\left[\widetilde{Y}_{c}\right]=-\frac{\overline{\sum_{k=1}^{N_{s p}}\left(n_{k} \rho^{*} Y_{k}^{*} V_{k}^{*}\right)}}{\rho_{0} D_{0} \frac{\partial \widetilde{Y}_{c}^{*}}{\partial x^{*}}}$,

$\Omega_{Y_{c}}^{a d}\left[\widetilde{Y}_{c}\right]=\overline{\rho_{0}^{*} S_{l}^{*} \frac{\partial Y_{c}^{*}}{\partial x^{*}}}-\overline{\rho_{0}^{*} S_{l}^{*}} \frac{\partial \widetilde{Y_{c}^{*}}}{\partial x^{*}}$

$\widetilde{\tilde{\omega}}_{Y_{c}}^{a d}\left[\widetilde{Y}_{c}\right]=\widetilde{\dot{\omega}}_{Y_{c}}^{*}$,

where the superscript $*$ denotes quantities issued from the computations of 1-D unstrained laminar premixed flames. The parameters $D_{0}$ and $\rho_{0}$ are reference parameters that are constant in time and space. They are chosen as the diffusivity and density in the fresh gases as proposed in [25]. This choice is conserved for all cases investigated. The Lewis number is not defined by the user in the present modeling strategy as the tabulation is performed from 1-D laminar premixed flames computed with detailed chemistry and the Hirschfelder and Curtiss [26] approximation for the diffusion fluxes. The impact of differential diffusion in the direction normal to the flame front, and in particular on the flame consumption speed, is therefore captured by the model [14]. The impact of preferential diffusion on the local mixture equilibrium properties, highlighted in [27-29] and promoted by $\mathrm{H}_{2}$ in the present study, is not captured by the F-TACLES model.

By construction, this model propagates the resolved flame front at the sub-grid scale turbulent flame speed $S_{T, \Delta}[14,18]$ :

$S_{T, \Delta}=\Xi_{\Delta} \gamma S_{l}^{0}$,

where $S_{1}^{0}$ is the adiabatic consumption speed of a freely propagating laminar premixed flame. The subgrid scale flame front wrinkling factor $\Xi_{\Delta}$ is modeled by the expression initially proposed by Charlette et al. [30]:

$$
\Xi_{\Delta}=\left(1+\min \left[\max \left(0, \frac{\Delta}{\delta_{l}^{0}}-1\right), \Gamma_{\Delta}\left(\frac{\Delta}{\delta_{l}^{0}}, \frac{u_{\Delta}^{\prime}}{S_{l}^{0}}, R e_{\Delta}\right) \frac{u_{\Delta}^{\prime}}{S_{l}^{0}}\right]\right)^{\beta}
$$

where $\operatorname{Re}_{\Delta}=\left(u_{\Delta}^{\prime} \Delta\right) / v$ and $u_{\Delta}^{\prime}$ are the subgrid scale Reynolds number and turbulence intensity, respectively, while $\delta_{l}^{0}$ is the laminar flame thickness. $S_{I}^{0}$ and $\delta_{I}^{0}$ were in practice estimated from adiabatic flamelets, therefore the impact of heat losses on the subgrid scale flame wrinkling is neglected. The efficiency function $\Gamma_{\Delta}$ [30] estimates the net straining effect of all turbulent scales smaller than $\Delta$. The exponent $\beta$ is set constant and equal to $\beta=$ 0.5 as initially prescribed in [31]. Recent studies [18,32,33] demonstrate that this value is not universal but can be accurately estimated through an dynamic procedure. The application of this dynamic procedure in the present case is non-trivial because nonadiabatic flame configurations, submitted to local extinctions, have not been explored yet. 
The coefficient $\gamma$ accounts for heat losses [14] and is defined as follows:

$\gamma=\frac{S_{l}(\Delta \tilde{h})}{S_{l}^{0}}$,

The enthalpy defect relative to the fresh gases is defined as $\Delta h=$ $h^{a d}-h$, where $h$ is the chemical plus sensible enthalpy and the superscript ad refers to adiabatic conditions. The laminar consumption speed at a given $\Delta h$ is calculated from burner-stabilized 1D flames [34]. In adiabatic flows, $\gamma$ equals 1 and decreases when heat losses slow down combustion chemistry, to the limit of a quenched flame for $\gamma=0$. Modeling details are given in [14].

Chemical look-up tables are computed with the REGATH thermochemistry package developed at the EM2C laboratory $[35,36]$ using the detailed chemical scheme from Lindstedt [37], which includes 29 species and 141 reactions. The chemistry tabulation procedure captures the impact of differential diffusion on the flame consumption speed by using the methodology developed in [14].

\subsection{Numerical setup}

Large Eddy Simulations are performed using the node-centered YALES2 low-Mach number code [38]. A centered fourth-order finite volume scheme is used for spatial discretization. Time integration of convective terms is performed using the TRK4 fourth-order scheme [39]. Closure of Reynolds stresses is performed using the SIGMA model [40].

The computational domain for all the non-reacting and reacting LES starts at $z=-20 \mathrm{~mm}$ as shown by the blue domain delimited in Fig. 1. The origin of the domain is located at the bluff-body tip indicated by the yellow dot in Fig. 1. The associated tetrahedral element mesh is composed of 8.6 million of nodes. The mean cell size in the flame front region evolves from $\Delta_{x}=0.25 \mathrm{~mm}$ to $\Delta_{x}=$ $0.5 \mathrm{~mm}$. A filter width $\Delta=3.5 \mathrm{~mm} \approx 8 \delta_{l}^{0}$, where $\delta_{l}^{0}=0.44 \mathrm{~mm}$ is the laminar flame thickness, is chosen to generate the filtered chemical database. It ensures a numerical resolution $\left(\Delta \geq 5 \Delta_{X}\right)$ of the filtered reactive layer sufficient to track the flame front propagation without introducing numerical artifacts. A refined mesh has also been generated to perform a mesh sensitivity analysis. For that purpose, the cell size have been divided by two everywhere in the computational domain. The resulting tetrahedral mesh is composed of 67.2 million nodes and its associated flame filter size is $\Delta=1.75 \mathrm{~mm} \approx 4 \delta_{l}^{0}$.

Mean velocity profiles prescribed in the inlet plane $z=-20$ $\mathrm{mm}$ have been extracted from a non-reacting simulation including the swirl injection device (see the red domain in Fig. 1). An effective bulk flow velocity within the LES of $U_{\text {bulk }}^{\mathrm{LES}}=14.1 \mathrm{~m} \mathrm{~s}^{-1}$ in both non-reactive and reactive cases is then ensured. An homogeneous and isotropic turbulent field (HIT) is superimposed to the mean velocity profiles. This HIT is generated from a spectrum [41] with an integral length scale $L_{t}=2.5 \mathrm{~mm}$ and a turbulence intensity equal to $10 \%$ of the bulk velocity. This turbulence intensity reproduces the RMS levels observed at $z=-20 \mathrm{~mm}$ in the full domain nonreacting computation.

Isothermal wall boundary conditions are imposed in the nonadiabatic simulations. As the wall temperature measurements only partially cover the combustor surface (see Fig. 2), linear interpolations and extrapolations are performed to provide complete temperature boundary conditions. Although the temperature of the bluff-body wall surface (rod tip) is imposed to $500 \mathrm{~K}$ (measured value), the wall surfaces within the injection tube are assumed adiabatic. Therefore, the preheating of the fresh gases within the injection tube is not considered in the present work. This assumption is reasonable since a simple convective heat transfer analysis estimates the elevation of the fresh gas temperature flowing near the heated tube to $\Delta T=+4 \mathrm{~K}$. It means that a solid-gas temperature gap of $200 \mathrm{~K}$ is not sufficient to preheat significantly the injected fresh gases in the present flow conditions.

\subsection{Initialization of the non-adiabatic LES}

The combustor geometry promotes large ORZ of the flow characterized by a high residence time in these regions. The typical turn-around time of the ORZ is $\tau_{\mathrm{ORZ}} \approx 40 \mathrm{~ms}$ [6]. The transient state required to reach steady-state thermal regime is therefore very long and remains out of reach for the LES. To overcome this issue, a RANS simulation is first performed with the Fluent commercial solver [42] using the same computational domain as for the LES but without considering chemical reactions. Burnt gases, which composition and temperature correspond to the adiabatic combustion of the fresh fuel/air mixture studied in the experiment, are directly injected through the feeding inlet to approximate the thermochemical state of the flow. As for the LES computations, the measured wall temperatures are imposed at the wall surfaces. Using this methodology, the time period needed to obtain converged statistics is optimized.

Figure 6 compares thermocouple measurements in the ORZ filled with burnt gases with RANS calculations. The good agreement between the RANS simulation and the experiments validates the prescription of the thermal boundary conditions used in the simulations. The mean temperature field obtained by the steady

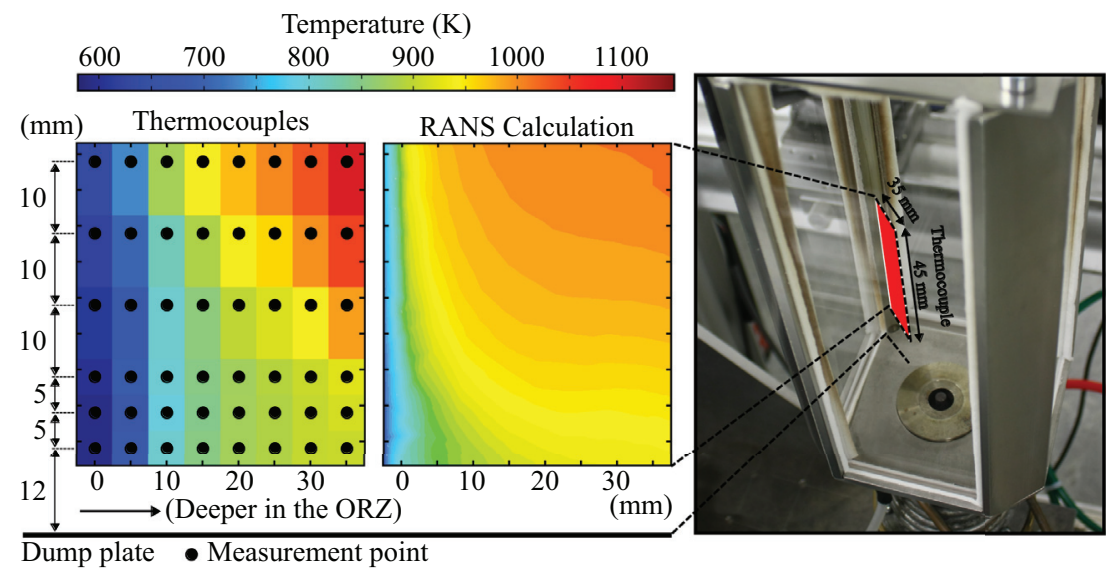

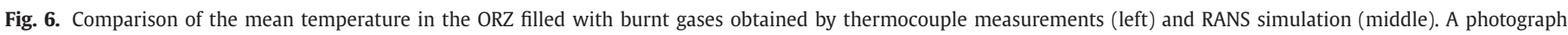
(right) of the combustion chamber delineates the positions of thermocouple measurements in the flow. 
RANS simulation is used to initialize the reacting non-adiabatic LES computation.

\subsection{Simulations performed}

A non-reacting simulation (SO) is first conducted to validate the ability of the computational setup to capture the flow dynamics. To analyze the impact of heat losses on the flame shape, two different LES of the reacting case $\mathrm{X}_{\mathrm{H}_{2}}^{\text {fuel }}=0.60$ are then performed using the F-TACLES model. The first one (S1) assumes an adiabatic burner while the second one (S2) accounts for heat losses at the walls. A mesh sensitivity analysis ( $\mathrm{S} 2 \mathrm{R}$ ) is conducted on this last case using the refined mesh introduced in Section 3.1. To understand the impact of a variation in fuel composition on the flame shape and stabilization process, a sensitivity analysis (S3) is also carried out to determine the impact of hydrogen enrichment on the flame shape. For that purpose, the fuel composition is increased from $\mathrm{X}_{\mathrm{H}_{2}}^{\text {fuel }}=0.60$ to $\mathrm{X}_{\mathrm{H}_{2}}^{\text {fuel }}=0.90$ while other operating conditions are

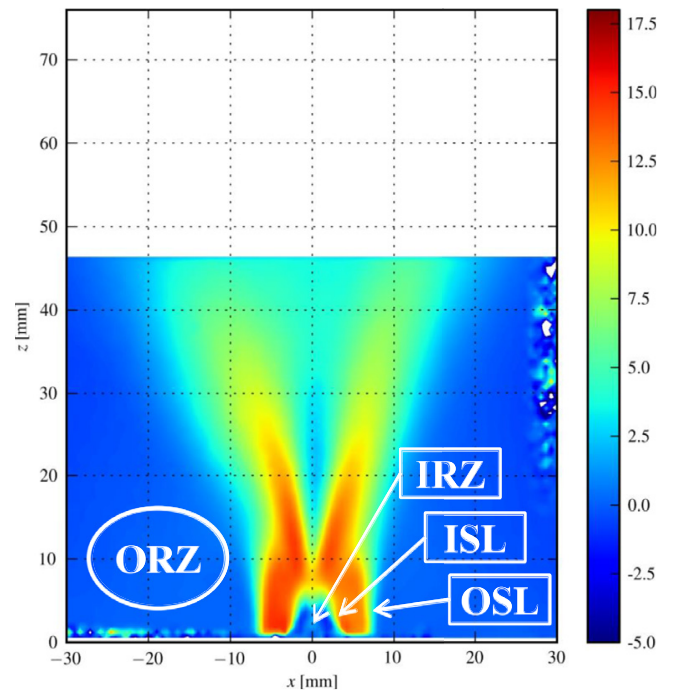

(a) PIV - Mean $U_{z}\left[\mathrm{~m} \cdot \mathrm{s}^{-1}\right]$ - Plane $y=0 \mathrm{~mm}$

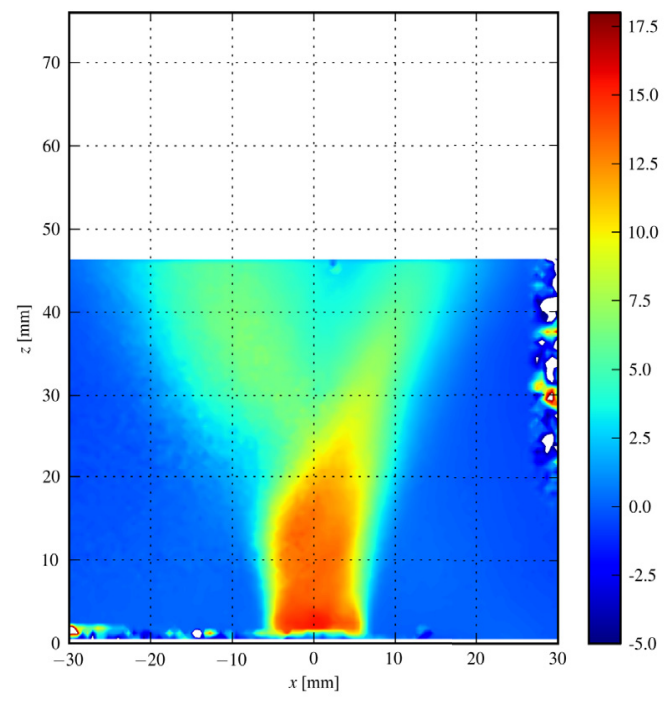

(c) PIV - Mean $U_{z}\left[\mathrm{~m} \cdot \mathrm{s}^{-1}\right]$ - Plane $y=4 \mathrm{~mm}$ kept constant. In this latter case, the flame takes an M shape. The list of LES performed is also indicated in Table 1.

\section{Analysis of the results}

\subsection{Non-reacting flow configuration}

Figure 7(a) and (c) shows the measured mean axial velocity field in two parallel longitudinal planes $(x, z)$ at two different positions along the $y$ direction, respectively ( $y=0$ and $4 \mathrm{~mm}$ ). The positions of the Inner Recirculation Zone (IRZ), Outer Recirculation Zone (ORZ), Inner Shear Layer (ISL), and Outer Shear Layer (OSL) are indicated in Fig. 7(a). The radial expansion of the jet due to the swirl imparted to the flow is also evidenced. As shown in Fig. 7(b) and (d), LES computation S0 captures well the mean flow topology. In particular the location and angle of the IRZ are well predicted at $y=0 \mathrm{~mm}$ around $z=6 \mathrm{~mm}$. The flow field structure at $z=40 \mathrm{~mm}$ is also well predicted except that the swirling jet arms

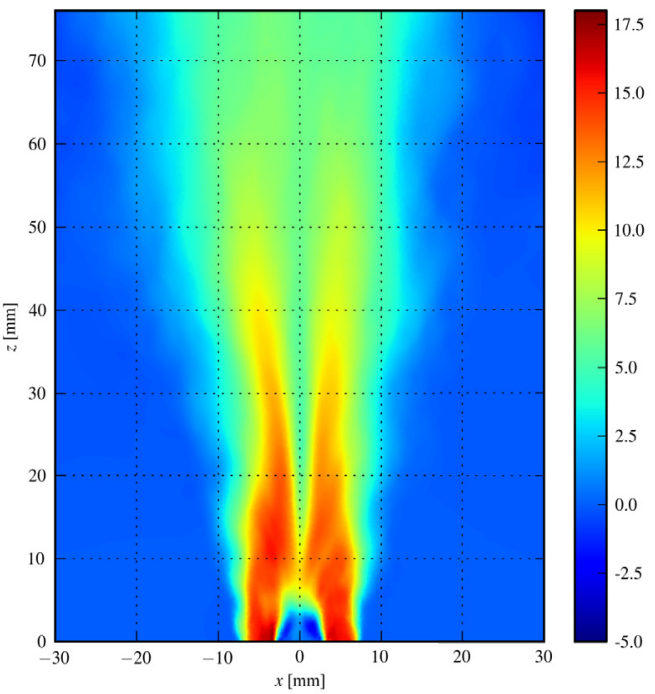

(b) LES - Mean $\widetilde{U_{z}}\left[\mathrm{~m} \cdot \mathrm{s}^{-1}\right]$ - Plane $y=0 \mathrm{~mm}$

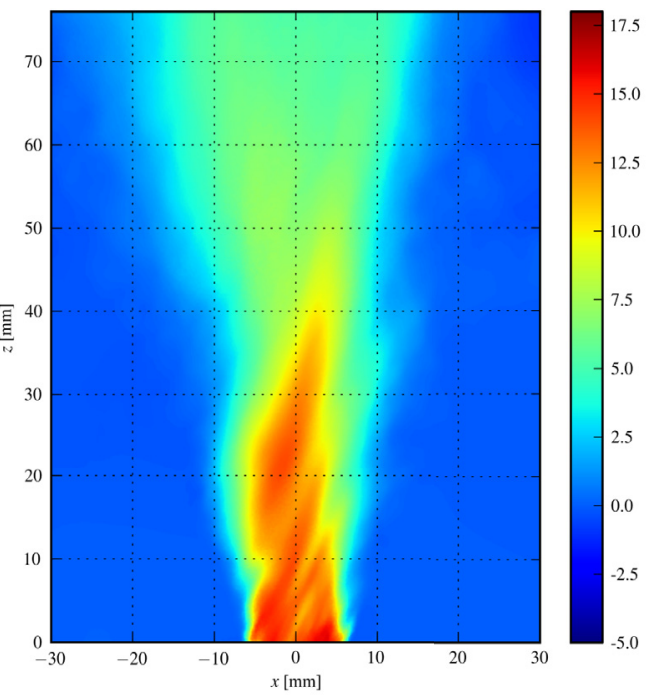

(d) LES - Mean $\widetilde{U_{z}}\left[\mathrm{~m} \cdot \mathrm{s}^{-1}\right]$ - Plane $y=4 \mathrm{~mm}$

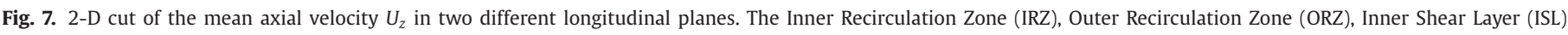
and Outer Shear Layer (OSL) are indicated in figure (a). 

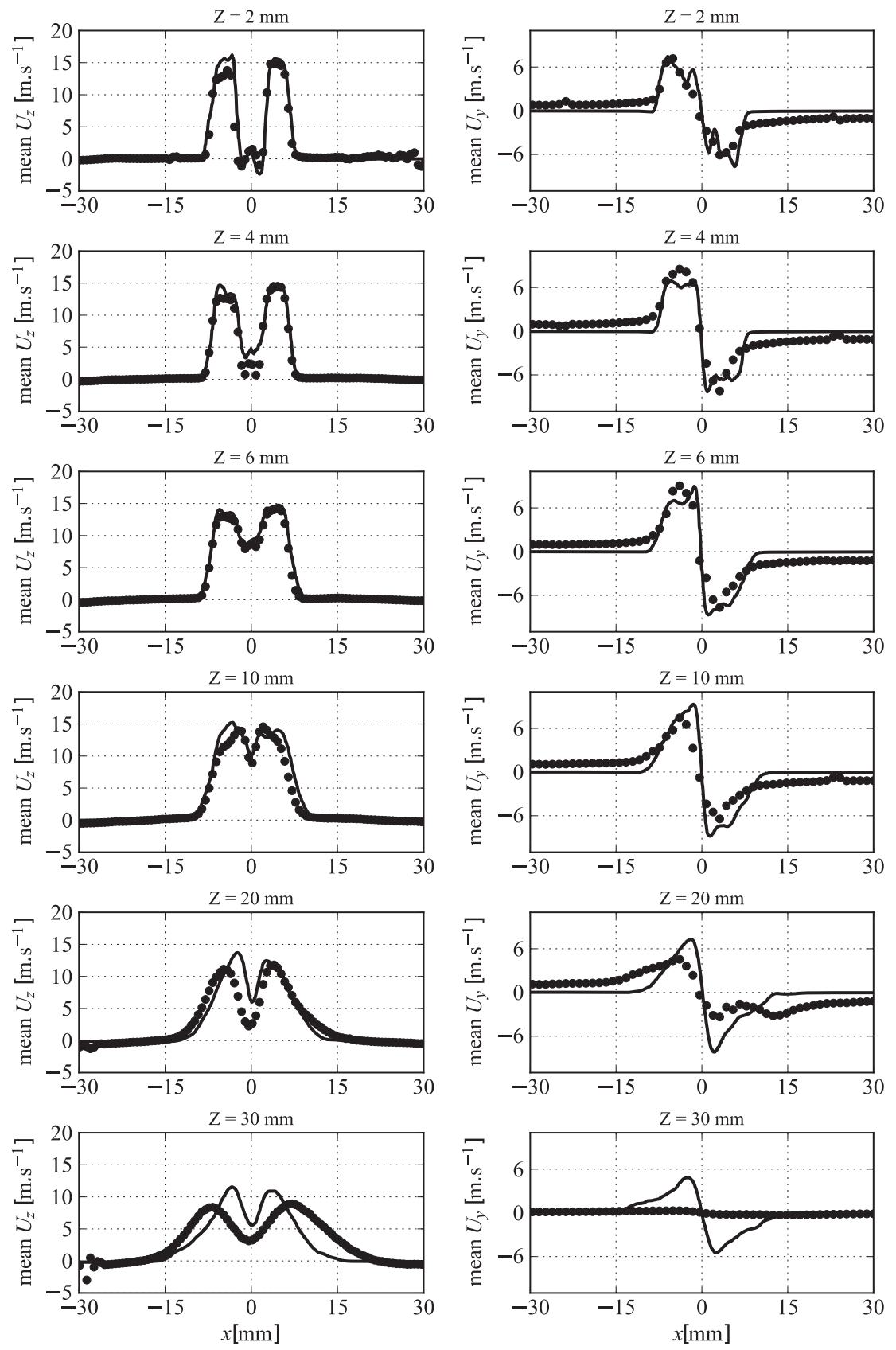

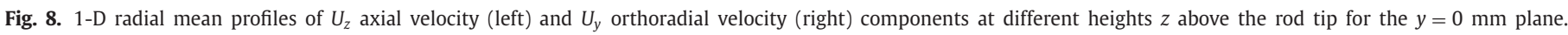
Black lines and black symbols correspond to simulation SO and PIV measurements respectively.

feature a slightly wider angle in the experiments. The good agreement between the experimental and numerical results remains valid for off-axis longitudinal planes, as shown in Fig. 7(c) and (d). However, simulations over-predict the axial velocity magnitude for $z>25 \mathrm{~mm}$. The quality of the PIV measurements at these locations is questionable because of the very low displacement of the particles between two laser pulses (low flow velocity). It is worth noting that, in the reacting cases discussed later, the flame is located far under the area where the velocity discrepancies appear. Wave patterns are observed in the outer shear layer in the mean numerical field of $U_{z}$. This is due to low frequencies shear flow instabilities within the outer shear layer that are not statistically converged.

Figure 8 shows the mean axial (left column) and orthoradial (right column) velocities in the axial longitudinal plane $y=0 \mathrm{~mm}$ at different axial positions $z$ above the burner. Both axial $U_{z}$ and orthoradial $U_{y}$ velocities are well predicted by the LES from $z=$ $0 \mathrm{~mm}$ to $z=20 \mathrm{~mm}$. The maximum axial velocity is reached by the jet at a radial position $|x|=5 \mathrm{~mm}$ and is $U_{z} \simeq 15 \mathrm{~m} \mathrm{~s}^{-1}$. Mean values of $U_{z}$ and $U_{y}$ at $z=2 \mathrm{~mm}$ are used to compute the simulated swirl number $S^{\mathrm{LES}}$ with the method given by [20] (Eq. (1)). The simulated and experimental swirl numbers are $S^{\mathrm{LES}}=0.31$ and $S^{P I V}=0.33$, respectively. The swirling motion is therefore correctly reproduced by the LES and the slight gap can be attributed to geometrical differences between the injector CAD and its real geometry [43].

Figure 9 plots a comparison between measured and computed Root Mean Square (RMS) axial (left column) and radial (right column) velocities. Large RMS values can be observed at $z=2 \mathrm{~mm}$ for $x<-15 \mathrm{~mm}$. This behavior, not seen in the LES results, should 

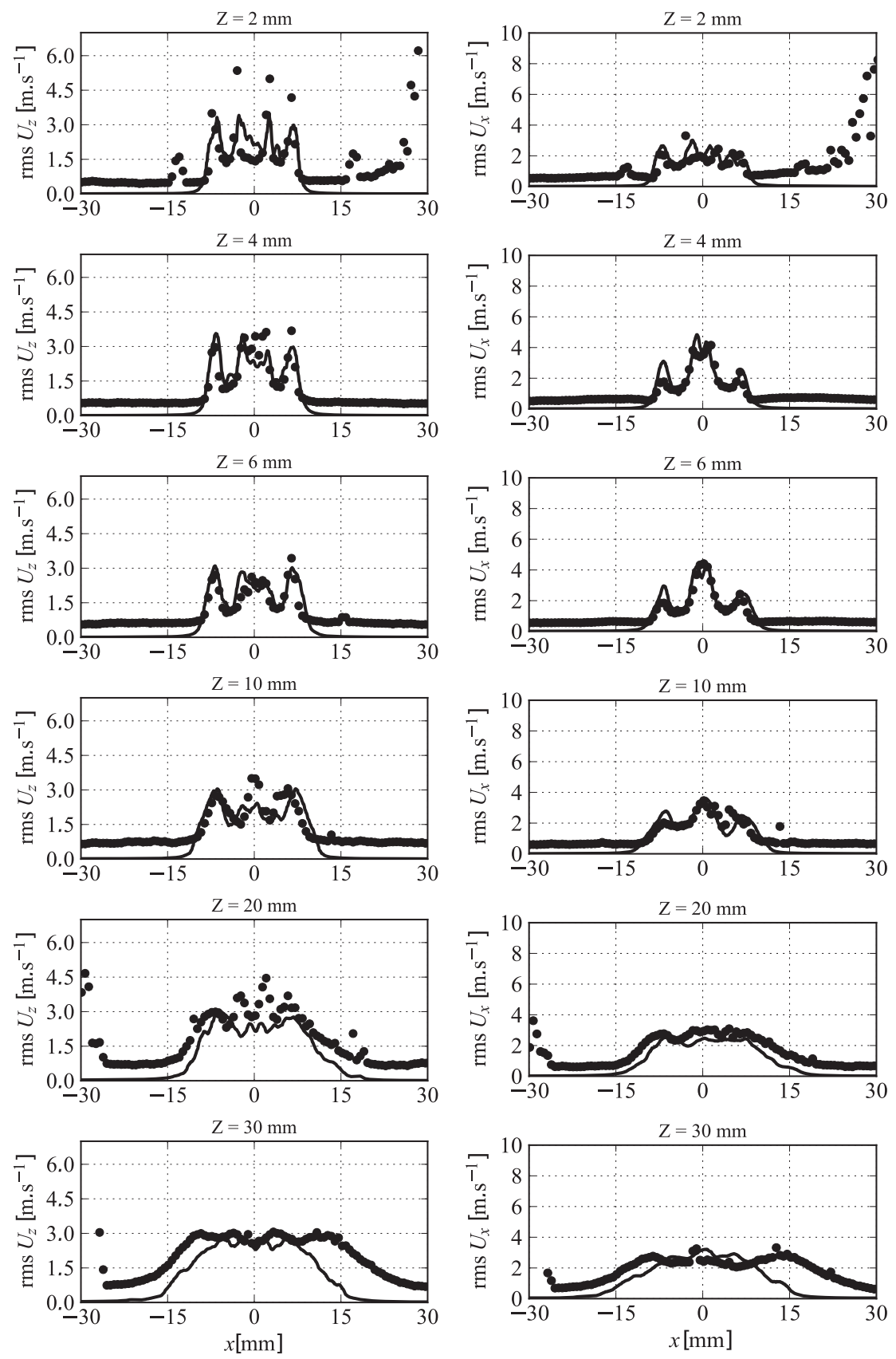

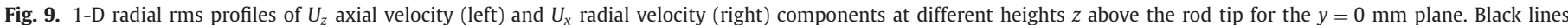
and black symbols correspond to simulation SO and PIV measurements respectively.

not be accounted for since it is a measurement artifact due to laser sheet reflections near the dump plate. The measured RMS components feature high values for $|z| \simeq 3 \mathrm{~mm}$ and $|z| \simeq 7 \mathrm{~mm}$ that correspond to the positions of the ISL and OSL. The maximum value of the axial rms velocity fluctuations is $U_{z}^{r m s} \simeq 5 \mathrm{~m} \mathrm{~s}^{-1}$, which corresponds to $36 \%$ of the bulk flow velocity $U_{\text {bulk }}=14 \mathrm{~m} \mathrm{~s}^{-1}$. LES predicts the position of these shear layers and the amplitude of the fluctuations. Differences between measurements and simulations increase for $z>20 \mathrm{~mm}$ where the rms fluctuations are underestimated in the simulations for $|r|>10 \mathrm{~mm}$.

The good agreement between measured and computed flow fields under non-reacting conditions validates the methodology retained to prescribe the velocity boundary conditions at the injection tube inlet $z=-20 \mathrm{~mm}$.

\subsection{Reacting flow configuration}

\subsubsection{Impact of heat losses on the flame topology}

The influence of heat losses on the turbulent flame structure is investigated through adiabatic (S1) and non-adiabatic (S2) simulations for the configuration with $\mathrm{X}_{\mathrm{H}_{2}}^{\text {fuel }}=0.6$. Figure 10 compares the normalized mean heat release rates predicted by both simulations with the $\mathrm{OH}^{*}$ chemiluminescence measurements. The measured and computed hot burnt gases probabilities (right plots) are also presented. Experiments exhibit a V flame shape, which is mainly due to local flame extinctions induced by wall heat losses. Burnt gases flowing inside the outer recirculation zone (ORZ) are cooled by the combustor walls. This leads to local flame extinction and promotes the transition from an $\mathrm{M}$ to $\mathrm{V}$ flame shape [6]. The 

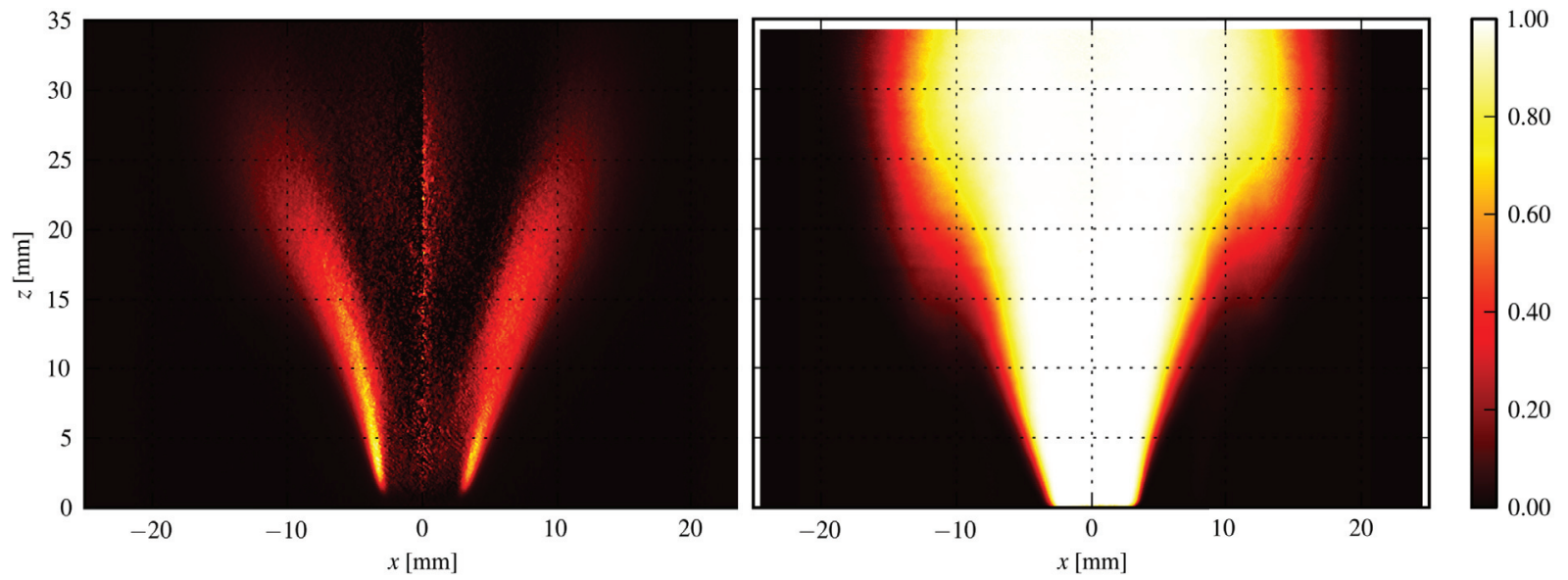

(a) Experiments. (left) Normalized Abel deconvoluted $\mathrm{OH}^{*}$ chemiluminescence. (right) Mean binarized OH-PLIF signal.

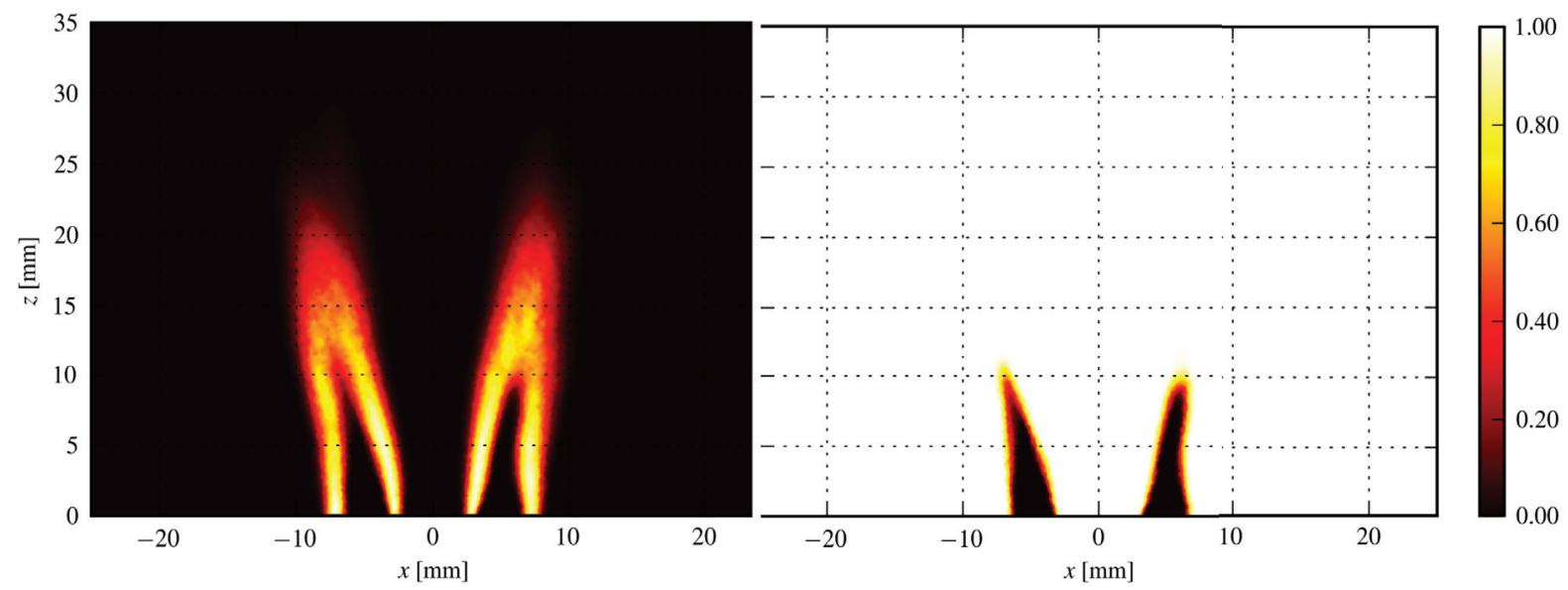

(b) Simulation S1. (left) Normalized mean volumetric heat release. (right) Mean binarized $\mathrm{OH}$ molar fraction.
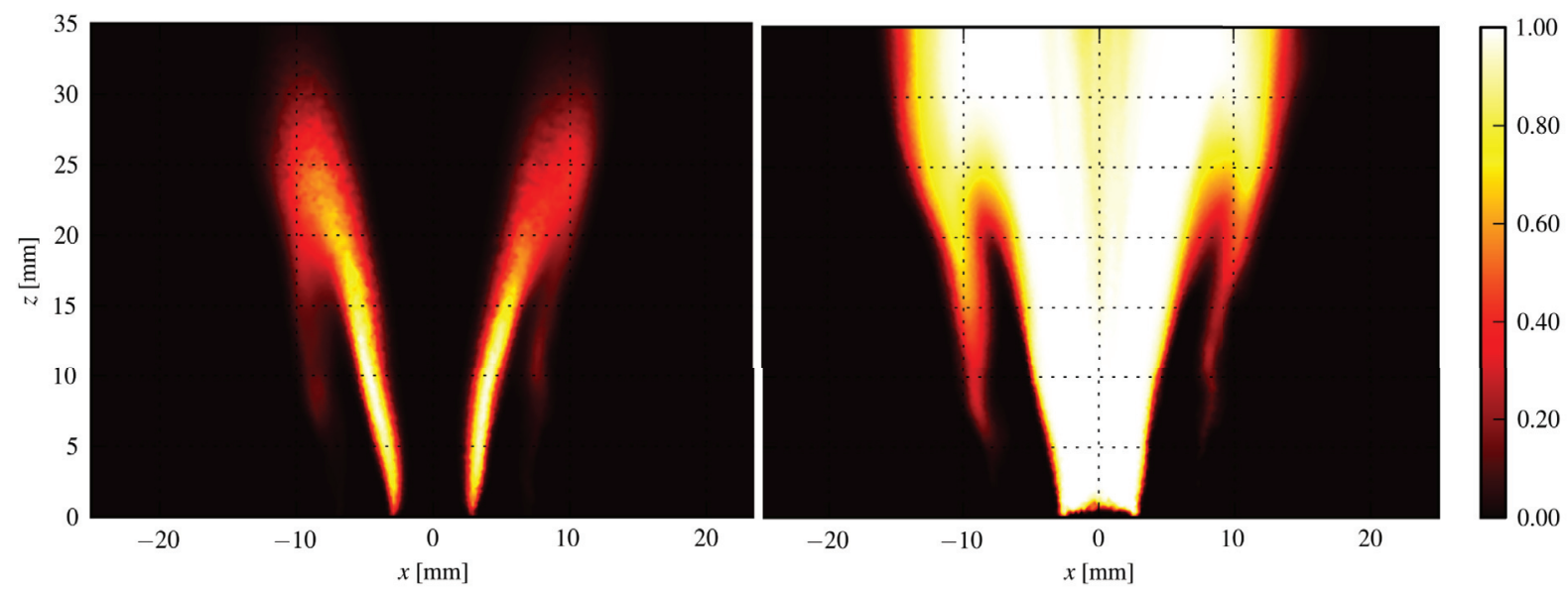

(c) Simulation S2. (left) Normalized mean volumetric heat release. (right) Mean binarized OH molar fraction.

Fig. 10. Comparisons of the mean flame position for the case $\mathrm{X}_{\mathrm{H}_{2}}^{\text {fuel }}=0.60$. Experiments, adiabatic ( $\mathrm{S} 1$ ) and non-adiabatic (S2) simulations results are shown.

adiabatic computation plotted in Fig. 10(b) cannot capture this phenomenon and consequently predicts an $\mathrm{M}$ flame shape where two reaction fronts are observed. The inner flame front is located in the ISL between the fresh stream of the reactant jet and the IRZ filled with burnt products above the bluff-body wall surface.
An outer flame front is hosted in the OSL between the fresh gas stream of reactants and the burnt gases in the ORZ. This prediction is not in agreement with the measurements shown in Fig. 10(a), where no reactive layer is observed in the OSL, leading to a $\mathrm{V}$ flame shape structure. 

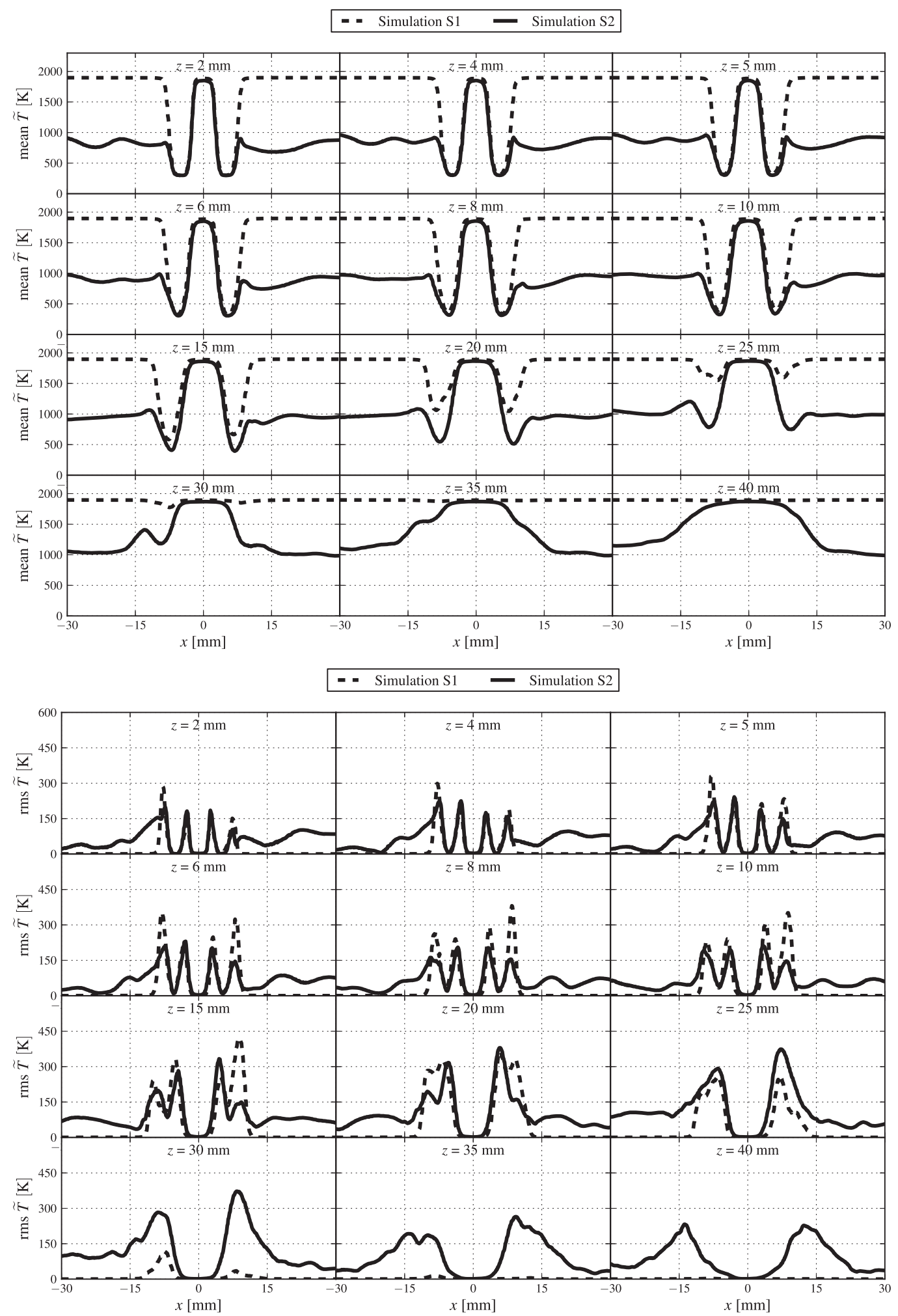

Fig. 11. 1-D radial profiles of temperature at different distances $z$ from the bluff-body wall surface for the case $\mathrm{X}_{\mathrm{H}_{2}}^{\text {fuel }}=0.60$. (top) Mean profiles. (bottom) RMS profiles.

The normalized mean volumetric heat release rate predicted by the non-adiabatic simulation (S2) is shown in Fig. 10(c). As the model accounts for the impact of heat losses on the chemical activity, the reactive layer intensity differs between the ISL and OSL. Indeed, heat losses induced by the sidewalls of the combustion chamber cool the burnt gases in the ORZ, which are convected to the OSL, decreasing the mixture reactivity [6]. Unlike S1 results, the outer flame front is not attached to the burner lips anymore. However, in contrast with experiments, a weak reactive layer still exists in the downstream OSL, near the flame tip. As discussed later in this section, additional quenching phenomena not captured by the F-TACLES model remain to be identified.

Figure 11 plots computed mean and rms temperature profiles at different distances above the bluff-body tip. Important differ- 

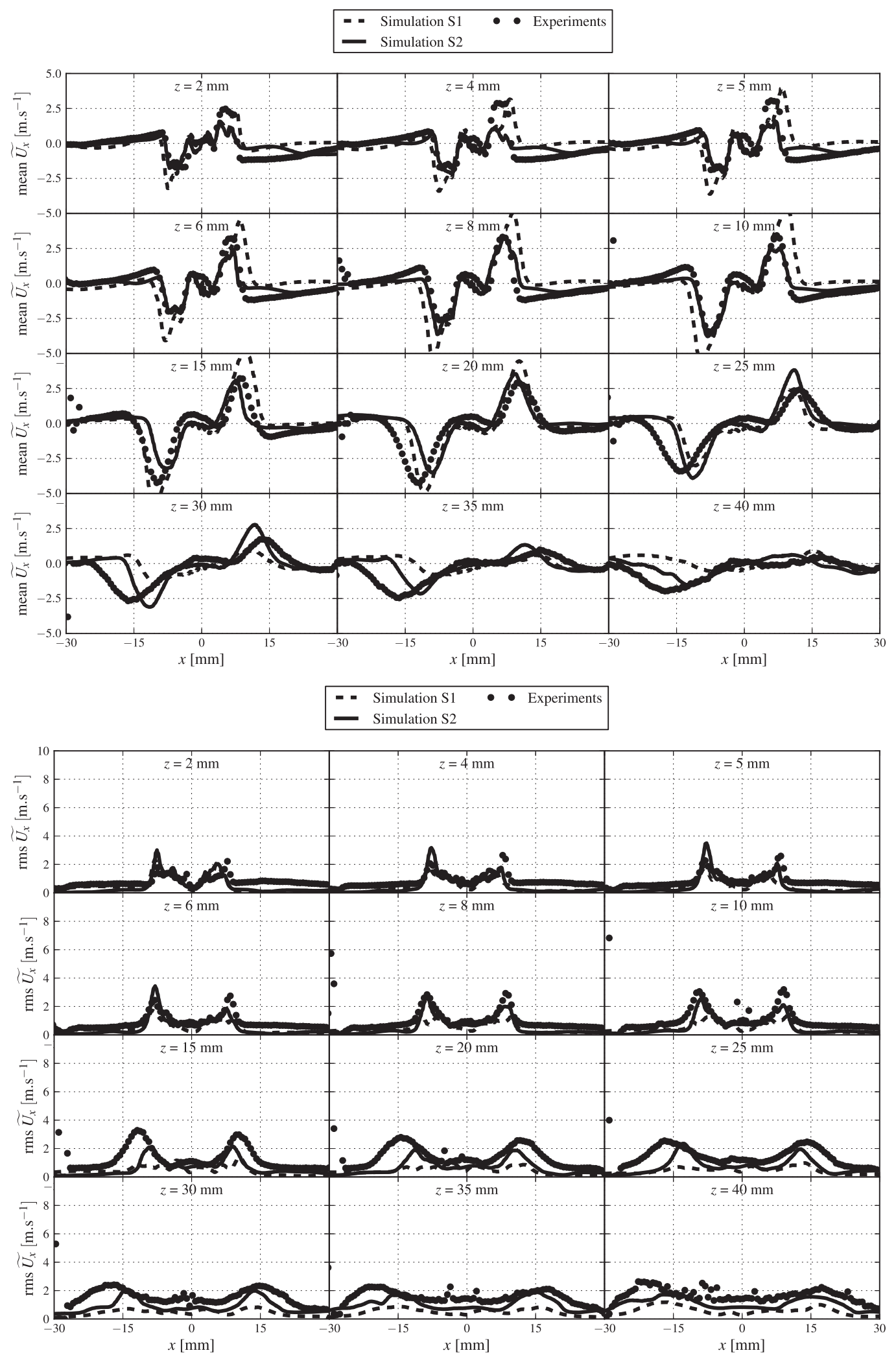

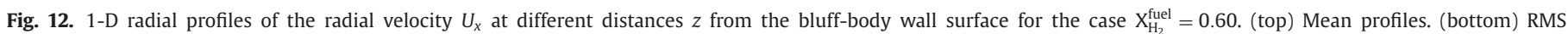
profiles.

ences are observed between mean temperature profiles predicted by both adiabatic and non-adiabatic LES. In particular, a difference of approximately $1000 \mathrm{~K}$ is observed in the very slow ORZ of the flow, for which an estimation of the characteristic time is $\tau_{\mathrm{ORZ}} \approx$ 40 ms [6]. During this recirculation time, hot gases exchange heat with the cooler combustion chamber side walls at $T_{\text {wall }} \approx 800 \mathrm{~K}$. It can also be noted that for the non-adiabatic computation S2, turbulent structures are mixing cold and hot burnt gases in the ORZ. This leads to important fluctuations of the temperature unlike the adiabatic computation S1. In both S1 and S2 computations, no 

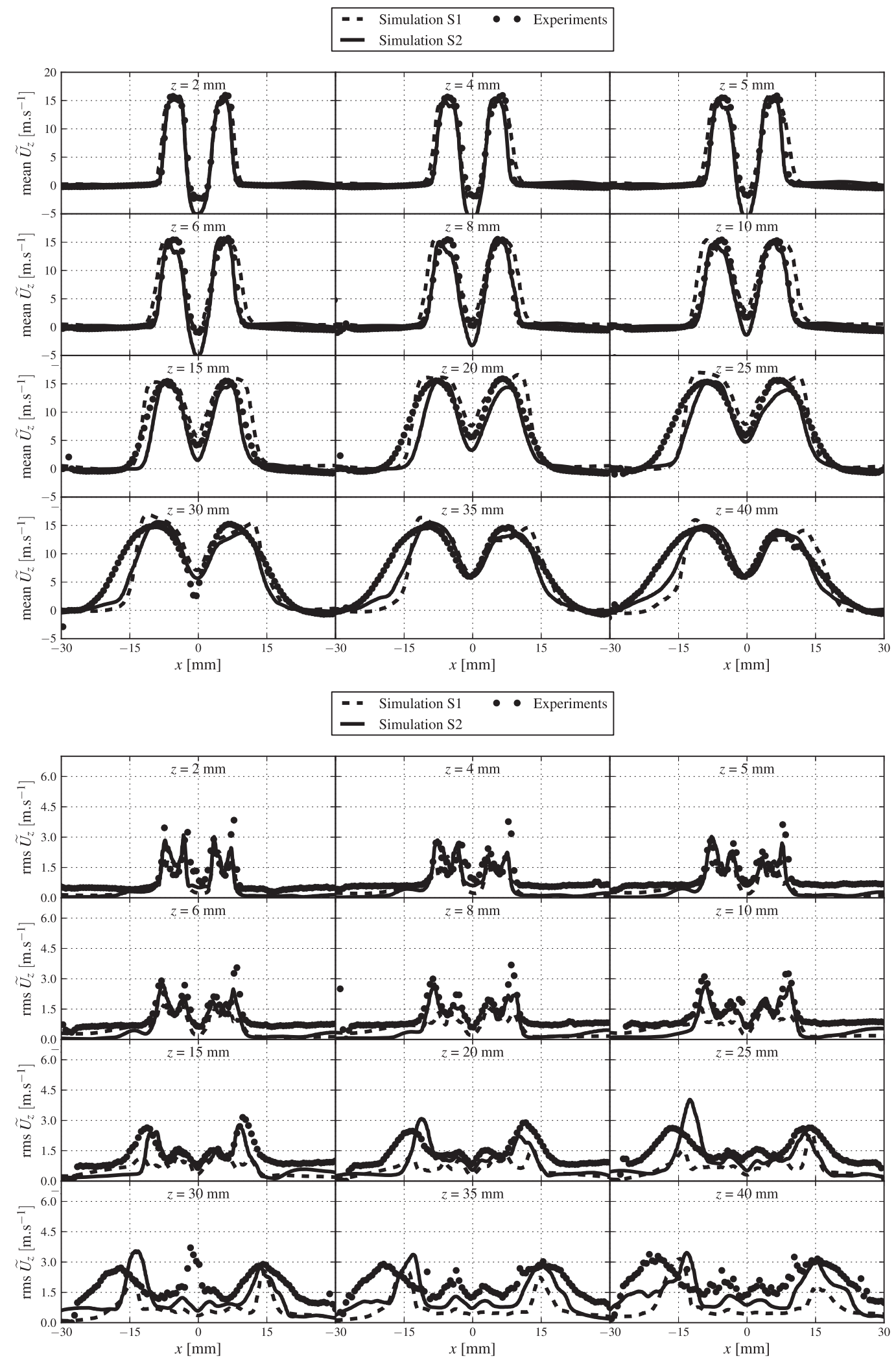

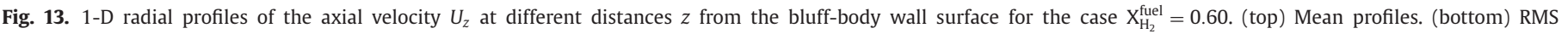
profiles.

temperature fluctuations are found in the IRZ. This may be explained by the stability of this recirculation zone and by the smaller gap between the temperature of burnt gases for both computations within the IRZ because of the limited surface area of the central rod.
The mean and RMS values of the radial and axial velocity components are shown in Figs. 12 and 13, respectively. In the present configuration, the radial velocity is an indicator of thermal expansion due to combustion. The presence of the outer flame front in the adiabatic simulation S1 causes an over prediction of the heat 

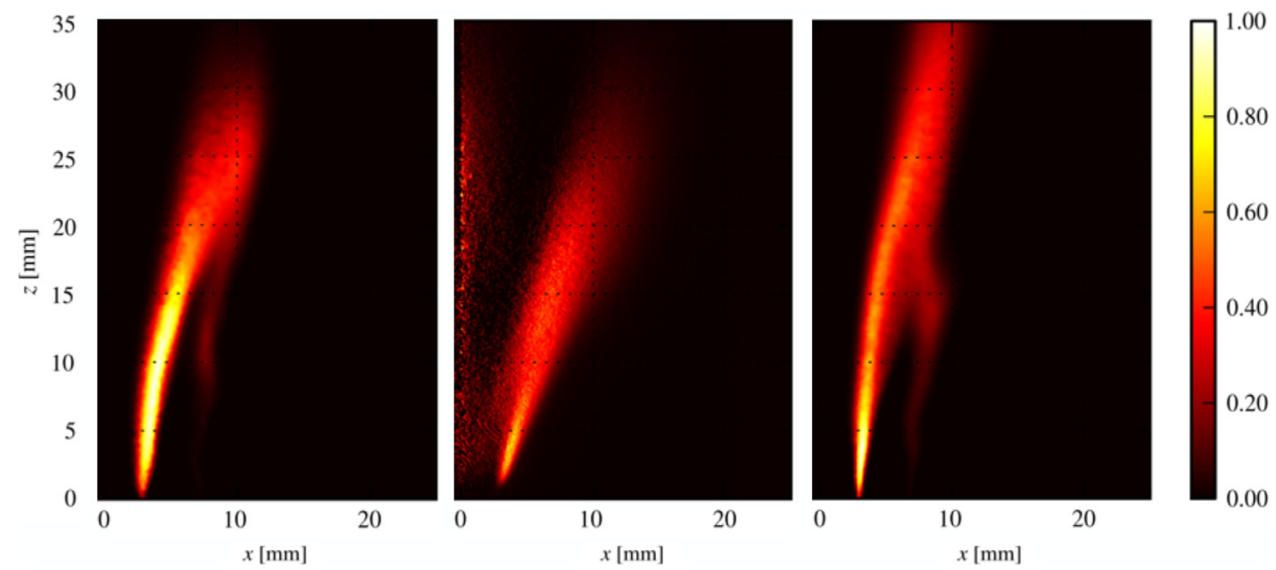

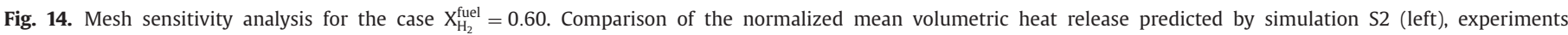
(middle) and the refined mesh simulation S2R (right).

expansion from $z=5 \mathrm{~mm}$ to $z=20 \mathrm{~mm}$. A better agreement with the experiments is obtained in the non-adiabatic simulation S2. The difference is also visible on the RMS velocity profiles. It means that the presence of the outer flame front in the OSL damps the fluctuations of the flow in the burnt gases unlike the non-adiabatic simulation, where heat expansion is reduced. These fluctuations are due to shear layer instabilities developing in the OSL between the injected stream of reactants and the slow ORZ. Differences are less visible on the mean and RMS axial velocity profiles shown in Fig. 13 which are both in good agreement with the experiments. The very low and negative mean axial velocities at large radial distances confirms the presence of the ORZ for all heights $z$ where the measurements have been performed.

Flame fronts stabilized in the OSL are more subject to extinction due to heat losses in comparison to those lying in the ISL as shown in [6]. This recirculation of cooler burnt gases corresponds to a low enthalpy region leading to a drop in the flame consumption speed and causes the flame extinction. The reaction process is then inhibited in the OSL leading to the extinction of the outer flame front and the stabilization of a V flame shape. This conclusion is corroborated by the results obtained in [8] on a similar configuration using RANS simulations. Heat losses were also identified in [7] as altering the flame shape of a swirl burner studied with and without confinement using a MILES approach.

A very small reaction zone is identified in the OSL regions of the non-adiabatic simulation S2, both in Fig. 10(c) and in the mean temperature profiles (Fig. 11, $z>15 \mathrm{~mm}$ and $x=10 \mathrm{~mm}$ ), where a slight temperature increase is observed. This reaction layer is an artifact, not observed in experiment, where the flame is quenched because of combined effect of strain and heat losses [44,45]. To capture this phenomenon, the present model should account for the impact of local strain rate on the flame consumption speed, which is very challenging because it occurs at the sub-grid scale.

\subsubsection{Mesh sensitivity analysis}

A homogeneous mesh refinement has been performed on the simulation S2 so that the refined cell size is twice finer than in the original mesh. The mean volumetric heat release rates are plotted in Fig. 14. For the simulation S2R, as the F-TACLES filter size has also been divided by a factor 2 , the impact of the sub-filter scale flame wrinkling is less important. The mesh refinement does not modify the prediction of the mean flame brush position. Indeed, the predicted flame angle is not impacted. However, it is worth noting that the distribution of the volumetric heat release rate is in better agreement with the experimental data shown in Fig. 10(a).
For $z<15 \mathrm{~mm}$, the mean heat release is more intense than for $\mathrm{z}>15 \mathrm{~mm}$ both in the experiment and refined mesh simulation $\mathrm{S} 2 \mathrm{R}$. This shift in heat release intensity is less perceptible in the reference mesh simulation S2 and only takes place for $\mathrm{z}>20 \mathrm{~mm}$. As the mean heat release rate is lower for $\mathrm{z}>15 \mathrm{~mm}$ in the S2R simulation, the mean flame length is slightly higher in this case. We also observe that the mesh refinement does not improve the prediction of flame quenching in the OSL.

\subsubsection{Impact of fuel composition on the flame topology}

The case $\mathrm{X}_{\mathrm{H}_{2}}^{\text {fuel }}=0.60$ considered in the experiments and simulations S1, S2, and S2R exhibits a V flame shape, only anchored on the central rod tip. The flame front lies in the inner shear layer (ISL) formed by the fresh combustible mixture jet and the IRZ filled with burnt gases. It was shown in [6] that increasing the molar fraction of $\mathrm{H}_{2}$ in the fuel $\mathrm{X}_{\mathrm{H}_{2}}^{\text {fuel }}$ continuously increases the probability $p$ to find a flame front in the OSL. In the present study, the $\mathrm{H}_{2}$ concentration is set to $\mathrm{X}_{\mathrm{H}_{2}}^{\text {fuel }}=0.90$ leading to a very high probability to find an $\mathrm{M}$ flame shape. Figure 15(a) shows the mean flame structure for $\mathrm{X}_{\mathrm{H}_{2}}^{\text {fuel }}=0.90$ using two different diagnostics. The left plot shows a mean Abel inverted $\mathrm{OH}^{*}$ chemiluminescence image while the right plot shows a mean binarized OH-PLIF result. The outer flame front in the OSL can clearly be identified in both images leading to an $\mathrm{M}$ flame shape. As suggested in [3], the increase in laminar burning velocity $S_{1}^{0}$ due to the increase of $\mathrm{X}_{\mathrm{H}_{2}}^{\text {fuel }}$ helps the reaction zone to propagate upstream through the OSL. The presence of the outer flame front in the OSL also depends on the stretch limit which is strongly extended when the Lewis number of the combustible mixture decreases [6] as it is the case when the fuel is enriched with hydrogen $[46,47]$.

Figure 15(b) shows the mean flame position predicted by the simulation S3. By accounting for both the effect of heat losses and hydrogen enrichments, the LES recovers the correct M flame shape observed in the experiment. There are however still differences between the experiment and the simulation. The flame length is slightly overpredicted in the simulation. In the experiment, the reactivity is elevated in the ISL and much lower in the OSL. The reactivity then progressively decreases towards the flame tip. In the simulation, the reactivity keeps high values in the ISL, but also in the OSL, except close to the flame tip where it drops rapidly. The turbulent flame brush in the experiment also spreads over a wider region than in the simulation. These differences might be attributed to the sub-grid scale wrinkling model that does not fully capture the flame wrinkling near the flame tip. As both flame fronts are located at the ISL and OSL, flame strain effects, which are 

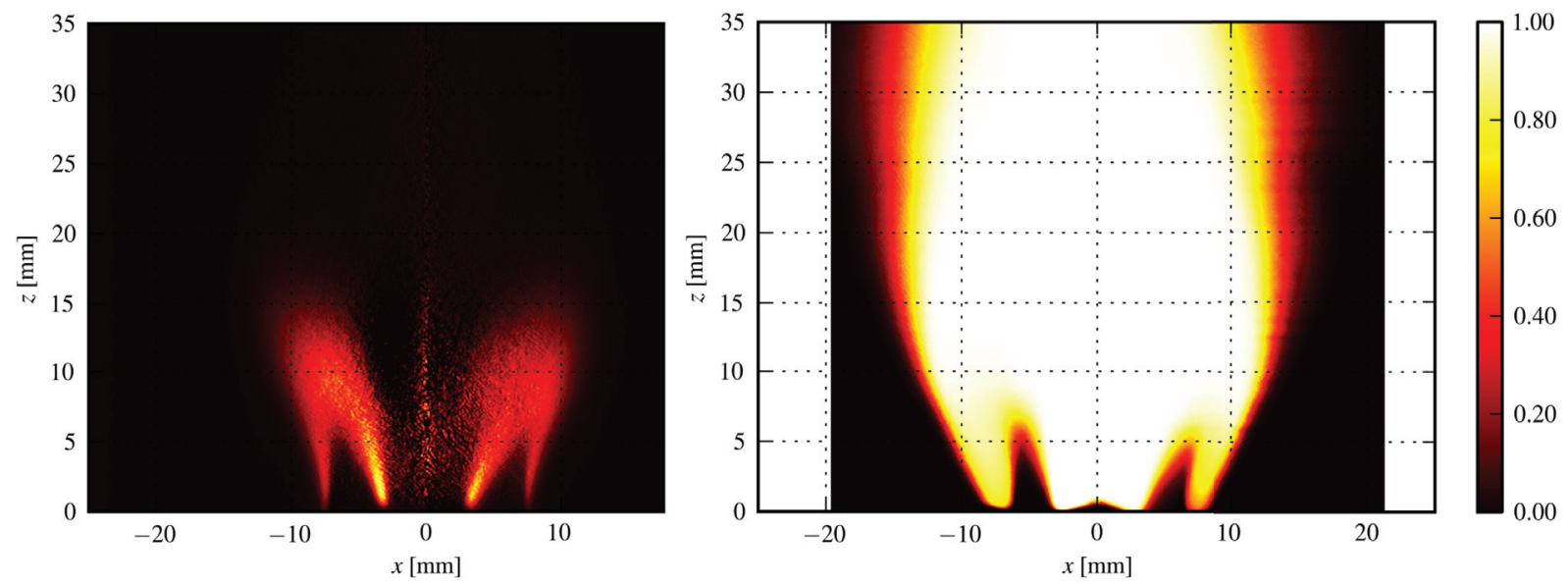

(a) Experiments. (left) Normalized Abel deconvoluted OH* chemiluminescence. (right) Mean binarized OH-PLIF.
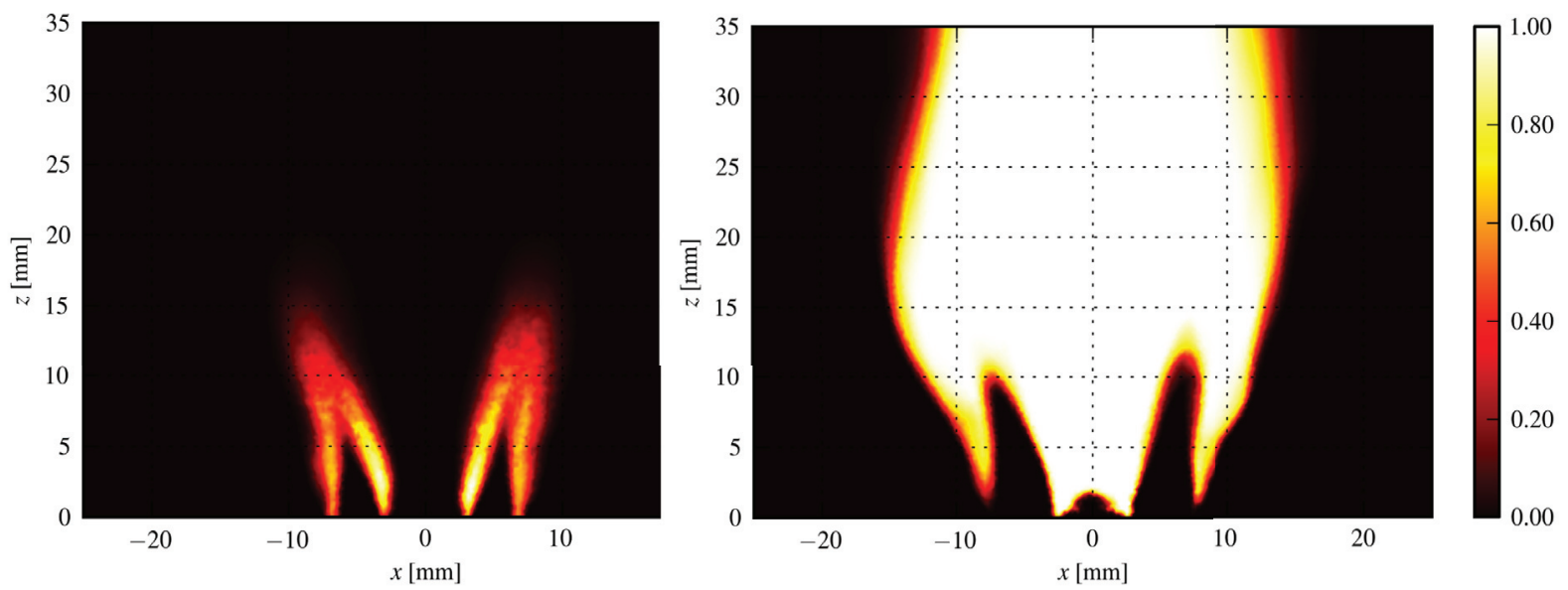

(b) Simulation S3. (left) Normalized mean volumetric heat release. (right) Mean binarized OH molar fraction.

Fig. 15. Comparisons of the mean flame position for the case $\mathrm{X}_{\mathrm{H}_{2}}^{\text {fuel }}=0.90$. Experiments and non-adiabatic simulation results are shown.

not accounted for by the F-TACLES model, may also explain the differences in reactivity. It is however worth recalling that the shape of the flame is well captured by the proposed methodology.

\section{Conclusions and perspectives}

An experimental configuration has been developed to challenge numerical simulations for capturing premixed swirling flame stabilization mechanisms in confined geometry. Large Eddy Simulations of this combustor have been performed using the turbulent combustion model F-TACLES, based on filtered premixed flamelet tabulation. Two configurations, with two levels of $\mathrm{H}_{2}$ enrichment in a $\mathrm{CH}_{4} / \mathrm{H}_{2}$ fuel blend, have been investigated. Experiments show that higher $\mathrm{H}_{2}$ concentration promotes flames with an $\mathrm{M}$ shape, whereas $\mathrm{V}$ shapes are observed for lower values of hydrogen enrichment. Assuming a fully adiabatic combustion chamber, LES always predicts an M flame shape. Another set of LES was performed accounting for measured thermal boundary conditions. These nonadiabatic LES predict the correct flame stabilization and show good agreement with experiments.

It was also found that the non-adiabatic simulation of the case $\mathrm{X}_{\mathrm{H}_{2}}^{\mathrm{fuel}}=0.60$ still predicts a low probability of having a flame front in the OSL, unlike in the experiments where this probability is zero. This slight difference suggests the importance of other physical phenomena in the $\mathrm{V}$ or $\mathrm{M}$ flame shape stabilization process. It might be due to the fact that the F-TACLES model does not explicitly account for the impact of local strain rate on turbulent consumption speed. In particular, the combined effects of strain rate and heat losses may influence the flame extinction within the OSL. In addition, as explained previously the influence of heat losses on the subgrid scale flame wrinkling has not been considered. This assumption should not impact the inner flame, which is almost adiabatic. However, at the outer flame location, where the flame is quenched due to heat losses, it may also explain the misprediction of local flame extinctions. Accounting for heat losses in the flame wrinkling modeling is a remaining issue which requires further investigations.

Ongoing experiments [5] indicate that in general the OSL only hosts a flame intermittently and its probability of presence $p$ decreases when the $\mathrm{H}_{2}$ concentration is progressively reduced in the fuel blend. For instance, the probability to find a flame front in the OSL is $p=0.01$ for the case $\mathrm{X}_{\mathrm{H}_{2}}^{\text {fuel }}=0.55$ and increases to $p=0.41$ for $\mathrm{X}_{\mathrm{H}_{2}}^{\text {fuel }}=0.78$. Two limit cases were studied herein $p=0.90$ for $X_{\mathrm{H}_{2}}^{\text {fuel }}=0.90$ with a well defined $\mathrm{M}$ flame shape and $p=0.01$ for $X_{\mathrm{H}_{2}}^{\text {fuel }}=0.60$ with a well defined $\mathrm{V}$ flame shape. In between these 
two limits, the physical processes leading to intermittent $\mathrm{M}$ to $\mathrm{V}$ and $\mathrm{V}$ to $\mathrm{M}$ flame shape bifurcations are not well understood and need to be further investigated.

\section{Acknowledgment}

This work was supported by the ANR-10-EESI-0005 Grant of the French Ministry of Research. Simulations were performed using HPC resources from GENCI-IDRIS (Grants 2013-x2013b0164 and 2015-x20152b0164). The YALES2 flow solver was made available through the GIS Success. Dr. Vincent Moureau and Dr. Ghislain Lartigue from the CORIA lab, and the SUCCESS scientific group, are also acknowledged for providing the YALES2 code.

\section{References}

[1] Y. Huang, V. Yang, Dynamics and stability of lean-premixed swirl-stabilized combustion, Prog. Energy Combust. Sci. 35 (4) (2009) 293-364. http://dx.doi. org/10.1016/j.pecs.2009.01.002.

[2] A.K. Gupta, D.G. Lilley, N. Syred, Swirl flows, Abacus Press, Tunbridge Wells, Kent, England, 1984, p. 488.

[3] K.T. Kim, J.G. Lee, H.J. Lee, B.D. Quay, D.A. Santavicca, Characterization of forced flame response of swirl-stabilized turbulent lean-premixed flames in a gas turbine combustor, J. Eng. Gas Turbines Power 132 (4) (2010) 041502.

[4] S. Terhaar, K. Oberleithner, C.O. Paschereit, Impact of steam-dilution on the flame shape and coherent structures in swirl-stabilized combustors, Combust. Sci. Technol. 186 (7) (2014) 889-911, doi:10.1080/00102202.2014.890597.

[5] T.F. Guiberti, D. Durox, L. Zimmer, T. Schuller, Analysis of topology transitions of swirl flames interacting with the combustor side wall, Combust. Flame 162 (11) (2015) 4342-4357, doi:10.1016/j.combustflame.2015.07.001.

[6] T.F. Guiberti, D. Durox, P. Scouflaire, T. Schuller, Impact of heat loss and hydrogen enrichment on the shape of confined swirling flames, Proc. Combust. Inst. 35 (2) (2015) 1385-1392.

[7] K.J. Nogenmyr, H.J. Cao, C.K. Chan, R.K. Cheng, Effects of confinement on premixed turbulent swirling flame using large eddy simulation, Combust. Theory Model. 17 (6) (2013) 1003-1019, doi:10.1080/13647830.2013.820842.

[8] L.T.W. Chong, M. Zellhuber, T. Komarek, H.G. Im, W. Polifke, Combined Influence of Strain and Heat Loss on Turbulent Premixed Flame Stabilization, Flow Turbul. Combust. 97 (1) (2015) 263-294, doi:10.1007/s10494-015-9679-0.

[9] F. Proch, A. Kempf, Modeling heat loss effects in the large eddy simulation of a model gas turbine combustor with premixed flamelet generated manifolds, Proc. Combust. Inst. 35 (3) (2015) 3337-3345. http://dx.doi.org/10.1016/j.proci. 2014.07.036.

[10] A. Donini, S. Martin, R. Bastiaans, J. van Oijen, L. de Goey, Numerical simulations of a premixed turbulent confined jet flame using the flamelet generated manifold approach with heat loss inclusion, Proc. ASME Turbo Expo 1A (2013). V01AT04A024. http://dx.doi.org/10.1115/GT2013-94363.

[11] B. Fiorina, D. Veynante, S. Candel, Modeling combustion chemistry in large eddy simulation of turbulent flames, Flow Turbul. Combust. 94 (2015) 3-42.

[12] P. Trisjono, K. Kleinheinz, H. Pitsch, S. Kang, Large eddy simulation of stratified and sheared flames of a premixed turbulent stratified flame burner using a flamelet model with heat loss, Flow Turbul. Combust. 92 (1-2) (2014) 201-235, doi:10.1007/s10494-013-9522-4.

[13] A. Ketelheun, G. Kuenne, J. Janicka, Heat transfer modeling in the context of large eddy simulation of premixed combustion with tabulated chemistry, Flow Turbul. Combust. 91 (4) (2013) 867-893.

[14] R. Mercier, P. Auzillon, V. Moureau, N. Darabiha, O. Gicquel, D. Veynante, B. Fiorina, Les modeling of the impact of heat losses and differential diffusion on turbulent stratified flame propagation: Application to the tu darmstadt stratified flame, Flow Turbul. Combust. 93 (2) (2014) 349-381, doi:10. 1007/s10494-014-9550-8.

[15] G. Kuenne, F. Seffrin, F. Fuest, T. Stahler, A. Ketelheun, D. Geyer, J. Janicka, A. Dreizler, Experimental and numerical analysis of a lean premixed stratified burner using 1d Raman/Rayleigh scattering and large eddy simulation, Combust. Flame 159 (8) (2012) 2669-2689, doi:10.1016/j.combustflame.2012. 02.010 .

[16] B. Fiorina, R. Mercier, G. Kuenne, A. Ketelheun, A. Avdic, J. Janicka, D. Geyer, A. Dreizler, E. Alenius, C. Duwig, P. Trisjono, K. Kleinheinz, S. Kang, H. Pitsch, F. Proch, F.C. Marincola, A. Kempf, Challenging modeling strategies for LES of non-adiabatic turbulent stratified combustion, Combust. Flame 162 (11) (2015) 4264-4282, doi:10.1016/j.combustflame.2015.07.036.

[17] B. Fiorina, R. Vicquelin, P. Auzillon, N. Darabiha, O. Gicquel, D. Veynante, A filtered tabulated chemistry model for LES of premixed combustion, Combust. Flame 157 (3) (2010) 465-475. http://dx.doi.org/10.1016/j.combustflame.2009. 09.015 .
[18] R. Mercier, T. Schmitt, D. Veynante, B. Fiorina, The influence of combustion SGS submodels on the resolved flame propagation. Application to the LES of the cambridge stratified flames, Proc. Combust. Inst. 35 (2) (2015) 1259-1267.

[19] D. Durox, S. Ducruix, F. Lacas, Flow seeding with an air nebulizer, Exp. Fluids 27 (5) (1999) 408-413, doi:10.1007/s003480050365.

[20] P. Palies, D. Durox, T. Schuller, S. Candel, The combined dynamics of swirler and turbulent premixed swirling flames, Combust. Flame 157 (9) (2010) 16981717, doi:10.1016/j.combustflame.2010.02.011.

[21] J. Brübach, C. Pflitsch, A. Dreizler, B. Atakan, On surface temperature measurements with thermographic phosphors: A review, Prog. Energy Combust. Sci. 39 (1) (2013) 37-60.

[22] T.L. Bergman, F.P. Incropera, A.S. Lavine, Fundamentals of heat and mass transfer, John Wiley \& Sons, 2011.

[23] V. Hindasageri, R. Vedula, S. Prabhu, Thermocouple error correction for measuring the flame temperature with determination of emissivity and heat transfer coefficient, Rev. Sci. Instrum. 84 (2) (2013) 024902.

[24] W. Ranz, W. Marshall, Evaporation from drops, Chem. Eng. Prog 48 (3) (1952) $141-146$.

[25] P. Auzillon, O. Gicquel, N. Darabiha, D. Veynante, B. Fiorina, A filtered tabulated chemistry model for les of stratified flames, Combust. Flame 159 (8) (2012) 2704-2717, doi:10.1016/j.combustflame.2012.03.006.

[26] J.O. Hirschfelder, C.F. Curtiss, R.B. Bird, M.G. Mayer, Molecular theory of gases and liquids, vol. 26, Wiley New York, 1954.

[27] A. Vreman, J. van Oijen, L. de Goey, R. Bastiaans, Direct numerical simulation of hydrogen addition in turbulent premixed Bunsen flames using flameletgenerated manifold reduction, Int. J. Hydrogen Energy 34 (6) (2009) 27782788. http://dx.doi.org/10.1016/j.ijhydene.2009.01.075.

[28] R.S. Barlow, M.J. Dunn, M.S. Sweeney, S. Hochgreb, Effects of preferential transport in turbulent bluff-body-stabilized lean premixed $\mathrm{CH}_{4}$ /air flames, Combust. Flame 159 (8) (2012) 2563-2575, doi:10.1016/j.combustflame.2011.11. 013.

[29] S. Nambully, P. Domingo, V. Moureau, L. Vervisch, A filtered-laminar-flame PDF sub-grid scale closure for LES of premixed turbulent flames. part i: Formalism and application to a bluff-body burner with differential diffusion, Combust. Flame 161 (7) (2014) 1756-1774. http://dx.doi.org/10.1016/j. combustflame.2014.01.005.

[30] F. Charlette, C. Meneveau, D. Veynante, A power-law flame wrinkling model for LES of premixed turbulent combustion. part I: non-dynamic formulation and initial tests, Combust. Flame 131 (2002) 159-180. http://dx.doi.org/10.1016/ S0010-2180(02)00400-5.

[31] F. Charlette, C. Meneveau, D. Veynante, A power-law flame wrinkling model for LES of premixed turbulent combustion. part II: Dynamic formulation, Combust. Flame 131 (2002) 181-197.

[32] G. Wang, M. Boileau, D. Veynante, Implementation of a dynamic thickened flame model for large eddy simulations of turbulent premixed combustion, Combust. Flame 158 (11) (2011) 2199-2213, doi:10.1016/j.combustflame.2011. 04.008.

[33] T. Schmitt, M. Boileau, D. Veynante, V. Moureau, Flame wrinkling factor dynamic modeling for large eddy simulations of turbulent premixed combustion, 8th International Symposium On Turbulence and Shear Flow Phenomena (2013).

[34] B. Fiorina, R. Baron, O. Gicquel, D. Thévenin, S. Carpentier, N. Darabiha, Modelling non-adiabatic partially-premixed flames using flame prolongation of ildm, Combust. Theory Model. 7 (3) (2003) 449-470, doi:10.1088/1364-7830/ $7 / 3 / 301$.

[35] L. Pons, N. Darabiha, S. Candel, G. Ribert, V. Yang, Mass transfer and combustion in transcritical non-premixed counterflows, Combust. Theory Model. 13 (1) (2009) 57-81, doi:10.1080/13647830802368821.

[36] S. Candel, T. Schmitt, N. Darabiha, Progress in transcritical combustion: experimentation, modeling and simulation, 23rd ICDERS, Irvine USA (2011).

[37] P. Lindstedt, 12 month progress report 1, tech. rep. tr-96 009. Brite Euram Program Project BRPR950056, 1997.

[38] V. Moureau, P. Domingo, L. Vervisch, Design of a massively parallel cfd code for complex geometries, C. R. Méc. 339 (2-3) (2011) 141-148.

[39] M. Kraushaar, Application of the compressible and low-mach number approaches to large eddy simulation of turbulent flows in aero-engines Ph.d. thesis, Université de Toulouse, 2011.

[40] F. Nicoud, H.B. Toda, O. Cabrit, S. Bose, J. Lee, Using singular values to build a subgrid-scale model for large eddy simulations, Phys. Fluids 23 (8) (2011). http://dx.doi.org/10.1063/1.3623274.

[41] T. Passot, A. Pouquet, Numerical simulation of compressible homogeneous flows in the turbulent regime, J. Fluid Mech. 181 (1987) 441-466, doi:10.1017/ S0022112087002167.

[42] ANSYS®fluent, Theory Guide, Release 12.0 (2009).

[43] J.F. Bourgouin, J. Moeck, D. Durox, T. Schuller, S. Candel, Sensitivity of swirling flows to small changes in the swirler geometry, C. R. Méc. 341 (1-2) (2013) 211-219. http://dx.doi.org/10.1016/j.crme.2012.10.018. 
[44] B. Coriton, J.H. Frank, A. Gomez, Effects of strain rate, turbulence, reactant stoichiometry and heat losses on the interaction of turbulent premixed flames with stoichiometric counterflowing combustion products, Combust. Flame 160 (11) (2013) 2442-2456. http://dx.doi.org/10.1016/j.combustflame.2013.05.009.

[45] L. Tay-Wo-Chong, M. Zellhuber, T. Komarek, H.G. Im, W. Polifke, Combined influence of strain and heat loss on turbulent premixed flame stabilization. Flow Turbul. Combust. (2015) 1-32, doi:10.1007/s10494-015-9679-0.
[46] E.R. Hawkes, J.H. Chen, Direct numerical simulation of hydrogen-enriched lean premixed methane-air flames, Combust. Flame 138 (3) (2004) 242-258. http: //dx.doi.org/10.1016/j.combustflame.2004.04.010.

[47] A. Lipatnikov, J. Chomiak, Molecular transport effects on turbulent flame propagation and structure, Prog. Energy Combust. Sci. 31 (1) (2005) 1-73. http: //dx.doi.org/10.1016/j.pecs.2004.07.001. 